
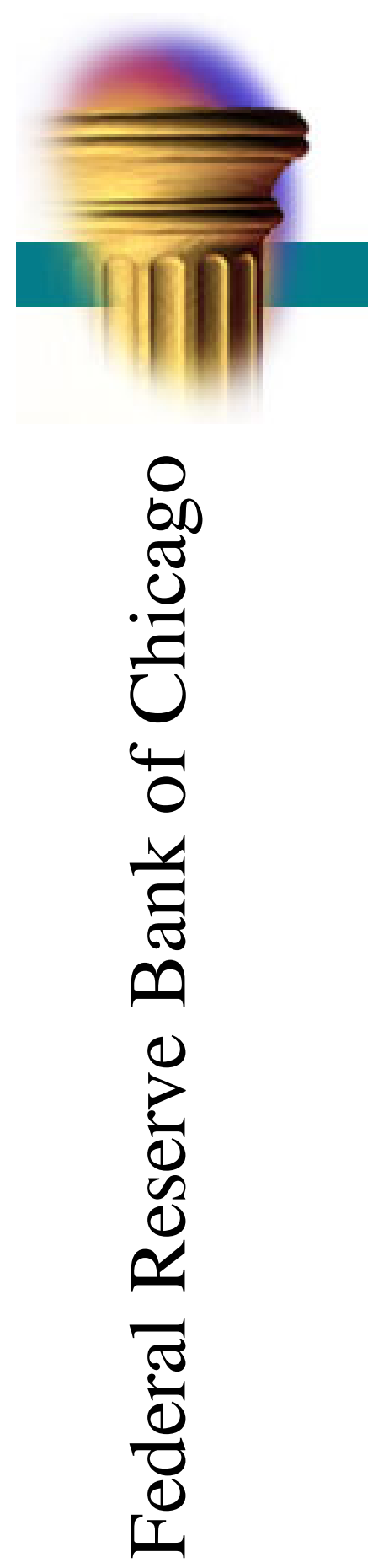

Impacts of the Fed Corporate Credit Facilities through the Lenses of ETFs and CDX

Stefania D’Amico, Vamsidhar Kurakula, and Stephen Lee

May 17, 2020

WP 2020-14

https://doi.org/10.21033/wp-2020-14

${ }^{*}$ Working papers are not edited, and all opinions and errors are the responsibility of the author(s). The views expressed do not necessarily reflect the views of the Federal Reserve Bank of Chicago or the Federal Reserve System. 


\title{
Impacts of the Fed Corporate Credit Facilities through the Lenses of ETFs and CDX*
}

\author{
Stefania D'Amico, Vamsidhar Kurakula, and Stephen Lee
}

May 17, 2020

\begin{abstract}
In this study, we use the liquid and efficient bond ETF prices and CDX spreads to quantify the effects of the announcements of the Primary and Secondary Market Corporate Credit Facilities on the underlying corporate bonds. We find that those announcements triggered: (i) large and positive jumps in the prices of directly-eligible ETFs as well as ETFs holding eligible bonds and their close substitutes; (ii) a discrete drop in the perceived credit risk of eligible bonds especially following the April $9^{\text {th }}$ announcement; (iii) a roaring back of investment-grade issuance and a pick-up in high-yield issuance. Importantly, across all ETFs in our sample, the magnitude of their price response does not seem directly related to the size of the reduction in either credit risk or liquidity risk, but rather appears to reflect mostly the eligibility of the ETF and its underlying bonds at the Federal Reserve facilities. This leads us to believe that the main factor driving the reaction to the announcements might be the elimination of "disaster risk" for eligible issuers.
\end{abstract}

Keywords: Balance Sheet Policy, Credit Easing, Corporate bond market. JEL classification: E43, E44, E52, E58.

\footnotetext{
* Stefania D’Amico (Federal Reserve Bank of Chicago; stefania.damico@ chi.frb.org), Vamsi Kurakula (Federal Reserve Bank of Chicago; vamsi.kurakula@chi.frb.org), Stephen Lee (Federal Reserve Bank of Chicago; steve.lee@chi.frb.org). The authors benefited from the comments and suggestions of Gene Amromin, Luca Benzoni, and Thomas King. We are also grateful to Stephanie Grove who helped us tracking all the news related to the $\mathrm{P}(\mathrm{S}) \mathrm{MCCF}$ in newspapers and dealer newsletters. The views expressed in this paper are those of the authors and do not necessarily reflect the position of the Federal Reserve Bank of Chicago, the Board of Governors, and the Federal Reserve System.
} 


\section{Introduction}

For the first time since the 1950s, the Federal Reserve (Fed) has waded into corporate credit markets to combat the coronavirus crisis. On March 23, 2020, the Fed announced a suite of new stimulus programs including two facilities aimed at helping directly the investment-grade (IG) corporate bond market. In particular, it announced that it would provide credit through the Primary Market Corporate Credit Facility (PMCCF) by buying bonds at issuance, and through the Secondary Market Corporate Credit Facility (SMCCF) by buying existing IG bonds in the secondary market as well as shares of exchangetraded funds (ETFs) tracking the IG bond market.

On April 9, the Fed extended the programs' eligibility to recently "fallen angels", that is, companies that were IG rated as of March 22, and subsequently downgraded to no lower than BB $\square$. The Fed also announced that it might buy a small amount of ETFs "whose primary investment objective is exposure to U.S. high-yield (HY) corporate bonds." Further, in the same announcement, the Fed indicated that the two facilities combined could reach up to $\$ 750$ billion in size - a significant share of the corporate-bond market. In particular, the PMCCF could provide as much as $\$ 500$ billion of primary credit, while SMCCF could purchase up to $\$ 250$ billion of existing bonds and ETFs.

Although it is not the first time that a central bank has intervened directly in the corporate bond market, ${ }^{1}$ a policy also known as credit easing (CE), the Federal Reserve is the first central bank to engage in purchases of bond ETFs. ${ }^{2}$ Given the sizable cross-section of bond ETFs in the U.S. and their liquidity and transparency, this type of intervention represents a unique laboratory to test how $\mathrm{CE}$ affects corporate bond markets, and an opportunity to shed some light on the current debate regarding the channels through which $\mathrm{CE}$ affects corporate borrowing.

In this study, we quantify the impact on the corporate bond market of the March 23 and April 9 announcements, whose unprecedented scope and size surprised most investors. The inclusion of bond ETFs in the Fed's purchase programs allows us to exploit this novel aspect of the Fed facilities to obtain more granular and precise measures of their impact on the underlying corporate bonds. Our analysis is conducted at the ETF level using most of the ETFs that track either the U.S. IG or the U.S. HY corporate bond markets. Our analysis of the ETFs' price and premium reaction to the two announcements is further augmented with the analysis of changes in CDX spreads around those same events. CDX are bundles of credit default swaps (CDS) but are completely standardized and exchange-traded, and therefore are a transparent and liquid measure of credit risk.

This approach has multiple advantages relative to previous event studies that estimate the impact of unconventional monetary policies in the corporate bond market. ${ }^{3}$ First, the use

\footnotetext{
${ }^{1}$ See for example the corporate purchase programs of the European Central Bank and Bank of England started in 2016.

${ }^{2}$ The Bank of Japan has been the first central bank to purchase stock ETFs in order to stimulate the equity market. See, for example, Harada and Okimoto (2019).

${ }^{3}$ See, for example, Gagnon et al (2011), Krishnamurthy and Vissing-Jorgensen (2011), Gilchrist et al. (2015)
} 
of very liquid and frequently-traded ETF prices and CDX spreads allows us to identify the direct impact of the $\mathrm{P}(\mathrm{S}) \mathrm{MCCF}$ by relying on intraday quotes that are not contaminated by the stale information present in corporate bond indices. That is, we are able to focus on changes that occur in short time windows around the announcements to eliminate other confounding factors. During the ongoing coronavirus crisis, the amount of news hitting financial markets every day has been extraordinary; therefore a highfrequency analysis is crucial to isolate the $\mathrm{P}(\mathrm{S}) \mathrm{MCCF}$ 's initial impact.

Second, the cross-sectional analysis at the ETF level allows us to exploit discontinuities created by the facilities' eligibility criteria. Relative differences in the effects across ETFs help us to gain insights on the magnitude and nature of the impacts on corporate bonds. Finally, by comparing the changes induced by the two announcements in various ETFs' characteristics, such as returns, premium/discount, and credit risks — proxied by a newly developed measure of "CDX" spreads at the ETF level — we can try to disentangle some of the transmission channels driving those changes.

Such high-frequency and granular analysis cannot be conducted at the bond level, as most individual corporate bonds tend to be illiquid and trade infrequently, especially in the midst of the current crisis. As pointed out in Greenwood, Hanson, and Liao (2018) and Mamaysky (2018), this type of high-frequency analysis tends to underestimate the impact of asset supply shocks in segmented markets, as prices of securities riskier than government bonds take longer to fully reflect those shocks. However, since our analysis employs the more liquid and efficient ETF prices, it should be less affected by those concerns. Moreover, further inspection of the discrepancy between ETF prices and underlying net asset values (NAV) over longer time intervals suggests that variations in ETF prices tend to lead NAV changes and mostly without reversal. This would indicate that most likely our event-study results do not understate the longer-term effects, except for those related to the eventual deviation between expected and actual Fed purchases.

Our findings indicate that in response to the announcements of $\mathrm{P}(\mathrm{S}) \mathrm{MCCF}$ there has been: (i) a large and positive jump in the prices of directly-eligible bond ETFs as well as ETFs holding eligible bonds or their close substitutes; (ii) a discrete drop in the perceived credit risk of eligible bonds especially following the April $9^{\text {th }}$ announcement; (iii) a roaring back of investment-grade issuance and a pick-up in high-yield issuance. All of those changes happened in response to the mere promise of future purchases of IG bonds and fallen angels, and suggest an average return per $\$ 100$-billion purchases of about $1.3 \%$ for IG bonds, of about $1.8 \%$ among fallen angels, and between $1.1 \%$ and $2.6 \%$ for $\mathrm{HY}$ bonds, with effects being larger for the lower-quality issuers. ${ }^{4}$ However, in the case of $\mathrm{HY}$ bonds, almost a third of those price increases retraced in the week following each announcement, thus those estimates might overstate the impact for lower-rated bonds. Importantly, across all ETFs in our sample, the magnitude of their price changes does not seem directly related to the size of the reduction in either credit risk (as measured by CDX spreads) or liquidity risk (as measured by the ETF premium/discount). Rather, it

\footnotetext{
${ }^{4}$ These estimates are obtained under the assumption that the "preponderance" of purchases will be in higher-quality bonds (i.e., IG and recent fallen angels) and IG bond ETFs, which we interpret as about 80\% of future purchases being allocated to those bonds and ETFs (i.e., a maximum of $\$ 600$ out of $\$ 750$ billion).
} 
seems to reflect mostly the eligibility of the ETF and its underlying bonds for purchase by one of the two Fed facilities. This leads us to conclude that the main factor driving the reaction to the announcements might be the elimination of "disaster risk" for eligible issuers, that is, the drastic reduction in the likelihood of an abrupt credit crunch, at least in the near term.

The rest of the paper is organized as follows. Section 2 reviews the literature closely related to this study. Section 3 briefly describes the eligibility criteria and how those changed between the two announcements. Section 4 focuses on the identification strategy. Section 5 details the data and variables used to analyze the ETF reaction to the announcements. Section 6 summarize the results. Finally, Section 7 offers some concluding remarks and ideas for future research.

\section{Literature Review}

Our work is related to various strands of the literature focused on central bank interventions in financial markets. First, our identification strategy is built on insights developed in the QE event study literature that analyzes how QE announcements affect the relative yields of individual securities rather than overall yields. See, for example, Bernanke (2020) for a careful review of this type of event studies.

Second, we contribute to the recent literature studying the effects of CE. Over the last decade, and up until March 2020, foreign central banks had gone further than the Fed and already purchased private securities. Analysis of these programs has found them to be an effective form of accommodation for the institutions targeted by the programs. For example, D'Amico and Kaminska (2019) consider the corporate bond purchases conducted by the Bank of England during the "Corporate Bond Purchase Scheme," which was launched at the same time as a new round of quantitative easing (QE), following the EU referendum result in 2016. They find that corporate bond prices responded substantially more to corporate bond purchases than to government bond purchases with similar maturities. This, in turn, leads CE to be more effective than QE in reducing credit spreads, especially for higher-rated bonds. The authors also find that, differently from QE, CE seems to stimulate new issuance of corporate bonds quite rapidly. ${ }^{5}$ This aspect of their findings is consistent with the evidence reported in recent studies of the ECB's "Corporate Sector Purchase Program" (see, Abidi and Miquel-Flores, 2018; Todorov, 2018; and Zaghini, 2019). In addition, Barbon and Gianinazzi (2019) and Charoenwong, Morck, and Wiwattanakantang (2020) study the purchases of stock ETFs conducted by the Bank of Japan, and find a positive and persistent impact on stock prices, consistent with a portfolio balance channel.

Third, our study is closely related to two contemporaneous studies, Nozawa and Qiuy (2020) and Haddad, Moreira, and Muir (2020), which analyze the impact of the COVID19 crisis and related Fed interventions in corporate bond markets. Differently from these studies, we do not analyze developments preceding the March 23 announcement, as we

\footnotetext{
${ }^{5}$ D'Amico and Kaminska (2019) find that QE does not seem to stimulate new issuance of corporate bonds over the programs' entire duration.
} 
are squarely focused on evaluating the impact of the Fed interventions, and we use a granular approach based on the cross-sectional variations at the ETF level, which allows us to exploit discontinuities created by the eligibility criteria to identify the $\mathrm{P}(\mathrm{S}) \mathrm{MCCF}$ effects.

Finally, we also learned a lot from the growing literature focused on ETFs. See, for example, Nam (2017), Lettau and Madhavan (2018), Dannhauser (2017), Flannery, Nimalendran, Ray, and Yousefi (2017), and Hao, Kim, Sul, and Wang (2019).

\section{Eligibility}

According to the March 23, 2020 announcement (8am ET)

The eligible assets include:

1) Corporate bonds

- Issued by U.S. companies headquartered in the U.S. and with material operations in the U.S. (for PMCCF) or U.S. businesses with material operations in the U.S. that will not receive direct financial assistance under pending federal legislation (for SMCCF);

- Rated IG by at least one major rating organization, but if rated by multiple organizations then by at least two;

- Having a maturity of four years or less for PMCCF and of five years or less for SMCCF;

2) U.S.-listed ETFs whose investment objective is to provide broad exposure to the market for U.S. IG corporate bonds.

According to the April 9, 2020 announcement (8:30am ET)

The eligible assets are expanded to include:

- Corporate bonds that were rated at least BBB- as of March $22^{\text {nd }}$, and were subsequently downgraded to no lower than BB-.

- U.S.-listed ETFs whose investment objective is to provide broad exposure to the market for U.S. HY corporate bonds.

And the following assets are excluded:

- Bonds issued by depository institutions or depository institution holding companies.

Importantly, the announcement also indicated that the Department of the Treasury's initial equity investment of $\$ 20$ billion is increased to a total of $\$ 75$ billion (split $\$ 50$ billion to the PMCCF and $\$ 25$ billion to the SMCCF) bringing the combined size of the two facilities to $\$ 750$ billion. This is because the facilities will leverage the Treasury equity 10 to 1 when acquiring IG corporate bonds and 7 to 1 when acquiring other eligible assets.

\section{Identification Strategy}


We use the rich and high-quality information derived from bond ETFs to increase our understanding of the impact of the two facilities on the markets for underlying securities, which are the main target of the $\mathrm{P}(\mathrm{S}) \mathrm{MCCF}$. In contrast to the underlying corporate bonds that are traded primarily in the opaque, dealer ("over-the-counter") market, bond EFTs trade intraday on electronic exchanges, therefore they offer a high degree of transparency. Further, many individual bonds are illiquid and trade infrequently, while bond ETFs typically offer greater liquidity and diversification. Due to these advantages, bond ETFs are attractive to individual bond buyers - either retail or institutional investors. ${ }^{6}$

Focusing on all ETFs that track the U.S. corporate bond market allows us to exploit discontinuities created by the facilities' eligibility criteria in the cross-section of the ETF reactions to the announcements. Our goal is to study not just how the two announcements affected the overall ETF characteristics but how they affected the relative characteristics of individual ETFs, which is key to the identification of the effects on the underlying bonds. ${ }^{7}$ According to the eligibility criteria described in Section 3, we start by dividing the bond ETFs in four broad categories. The first category includes what we define as "fully-eligible" ETFs, as both the ETF and its underlying securities are eligible for purchase. According to both announcements, IG ETFs are fully eligible. The second category includes what we define as "bond-eligible" ETFs, as the ETF is not eligible but a share of its underlying securities is eligible for purchase. According to the first announcement, (ineligible) HY ETFs that track shares of BBB-rated bonds are bond eligible. The third category includes what we define as "ineligible" ETFs, as neither the ETF nor its underlying securities are eligible for purchase. According to the first announcement, HY ETFs with no holdings of IG bonds are ineligible. The fourth category includes what we define as "newly-eligible" ETFs, as the ETF and a share of its underlying securities (those rated no lower than $\mathrm{BB}-$ ) become eligible for purchase because of the expanded eligibility criteria. According to the second announcement, HY ETFs are newly eligible. It is worth keeping in mind that on April 9 all the bond-eligible and ineligible ETFs became newly-eligible ETFs.

Why do these categories matter? Because, if the Fed facilities and hence their eligibility criteria are relevant to bond investors, we expect ETFs in the four categories to react differently to the two announcements. In the case of the fully-eligible ETFs, the change in any of the IG ETF's characteristics could reflect expectations of future purchases of both the ETF and its underlying securities, and thus these changes could overstate a bit the impact of the Fed facilities on the IG corporate bonds. As a result, we consider the average impact on the fully-eligible ETFs as an upper bound of our estimates for IG bonds. In the case of the bond-eligible ETFs, the change in any of the ETF's characteristics should reflect only expectations of future purchases of the underlying IG securities, and since these HY ETFs hold only a small share of IG bonds, we consider the

\footnotetext{
${ }^{6}$ As indicated in Nam (2017), for retail investors, the transaction cost associated with trading an individual junk bond averages 110 basis points and the minimum trading size for individual bonds is $\$ 100,000$ at a major brokerage firm. In sharp contrast, with the introduction of ETFs, investors can trade an entire portfolio at a cost of 1 basis point with an investment as small as $\$ 1,000$.

${ }^{7}$ D'Amico and King (2013) pioneered this approach in the context of the Federal Reserve's Treasury purchases during the first round of $\mathrm{QE}$.
} 
average impact on the bond-eligible ETFs as a lower bound of our estimates for IG bonds. Further, the average impact on the newly-eligible ETFs, could reflect expectations of future purchases of both the HY ETF and its underlying HY securities, and therefore could overstate a bit the impact of the Fed facilities on HY corporate bonds. Finally, if the $\mathrm{P}(\mathrm{S}) \mathrm{MCCF}$ announcements are the only factors driving changes in the ETFs' characteristics, we would expect to observe on average no change in ineligible ETFs, or maybe even a deterioration of some of their characteristics relative to those of the eligible ETFs.

Importantly, it should be considered that if ETF purchases simply accelerate and magnify the transmission mechanism of the Fed purchases to the underlying bonds, including those not eligible for purchase, then the potential "upper bias" introduced by the direct purchase of ETFs is not necessarily a reason for concern, as that upper bias would simply be part of the overall impact on the underlying corporate bonds and their close substitutes. For example, it is conceivable that, even if the Fed will not purchase directly corporate bonds issued either by depository institutions or with maturity longer than five years, it will indirectly affect those bonds by purchasing ETFs that invest in them. However, since by using ETFs, we want to capture only the impact on the underlying bond market, it is worth keeping in mind those considerations about possible biases.

Overall, relative differences in the ETF reactions allow us to identify a range of effects on corporate bonds and the main factors driving those effects. This is also because our identification strategy is quite flexible as it is not limited by the aforementioned four categories. For example, we can further refine the ranking of the ETFs based on some specific factor we are investigating, say credit risk, and verify whether the ETF price reaction in increasing or decreasing with this specific factor. Further, within each category, ETFs can be ordered by an increasing probability of being affected by the Fed's future purchases of corporate bonds, enhancing our ability to identify the impact of the $\mathrm{P}(\mathrm{S}) \mathrm{MCCF}$. For example, under the assumption that IG bonds have a higher likelihood of being purchased in relatively larger quantities by the two facilities, we should expect the ETFs with a higher share of IG bonds in their portfolios to react relatively more to the announcements. And, since all of this information about the ETFs' portfolio is publically available, we can order ETFs by their share of IG bonds and simply verify our assumption. The rest of this study is dedicated to testing, through our identification strategy, a sequence of hypotheses relevant to the estimation of the $\mathrm{P}(\mathrm{S}) \mathrm{MCCF}$ effects.

\section{Data}

We assemble a universe of fixed-income ETFs whose focus is on the U.S. corporate bond market, and additionally have fund assets of at least $\$ 10$ million. ${ }^{8}$ From Bloomberg, we then collect intraday share prices for each fund, as well as end of day net asset value (NAV) and fund flows. To distinguish the underlying assets, we also collect the most important characteristics of each ETF's underlying portfolio, such as the share invested in each rating category and industrial sector.

\footnotetext{
${ }^{8}$ For detailed information on ETFs see Lettau and Madhavan (2018) and Poterba and Shoven (2002).
} 
This leaves us with 87 ETFs, of which 53 are rated investment grade, and 34 are rated high yield. We have excluded corporate bond ETFs that have large holdings of securities other than corporate bonds. For example, ETFs that are "inflation hedged" or invest heavily in interest rate derivatives.

To proxy changes in credit risk for the underlying corporate bonds, we take advantage of ratings variation in the IHS Markit credit default swap indices (CDX). These exchangetraded products are constructed as baskets of credit default swaps (CDS) that are representative of a particular rating category. ${ }^{9}$ For example, two of the most liquid products are the CDX.NA.IG and CDX.NA.HY indices, which seek to provide insurance against a credit event for a bundle of investment grade and high yield corporate bonds, respectively. Importantly, these products "roll" - or reshuffle the basket of underlying CDS contracts - twice a year to ensure the indices represent the most liquid CDS contracts available, and to replace any contracts that fell out of the index (as a result of a bankruptcy, for example). ${ }^{10}$ The advantage of these two credit risk products is the availability of very high-frequency quotes that allow us to gauge the initial change in credit risk due exclusively to the $\mathrm{P}(\mathrm{S}) \mathrm{MCCF}$-related announcements.

In addition, three subsets of the two main indices are available: CDX.NA.IG.BBB, CDX.NA.HY.BB, and CDX.NA.HY.B. These seek to provide insurance against a credit event for the BBB-, BB-, and B-rated corporate bonds, respectively. Unfortunately there are no $\mathrm{CDX}$ indices for rating categories above $\mathrm{BBB}$ and below $\mathrm{B}$, therefore we will build those using only the CDS contracts already included in the available CDX indices. The final goal is to construct for each ETF a unique linear combination of these CDX indices to reflect its overall exposure to the credit risk of the various rating categories. We favor this approach because CDX indices explicitly focus on bundles of the most liquid and representative $C D S$ in each rating category, ${ }^{11}$ therefore should allow us to obtain an ETF-level measure of credit risk that minimizes the influence of the CDX-CDS basis - the difference between the spread on the CDX index and the spread implied by a replicating portfolio of CDS contracts. Junge and Trolle (2015) argue that the CDX-CDS basis measures the overall liquidity of the CDS portfolio. Hence, by using only the CDS contracts included in the various CDX indices, we hope to minimize the impact of changes in the liquidity risk of single CDS relative to the overall change in the credit risk of each rating category.

To do so, we partition the CDX.NA.IG into two distinct sets of CDS contracts: those included in CDX.NA.IG.BBB and those not included. This leaves us with two mutually exclusive bundles of investment-grade CDS contracts - those rated above BBB and those rated exactly BBB. ${ }^{12}$ Similarly, we partition the CDS contracts in the CDX.NA.HY into three categories that correspond to the ratings BB, B, and below B. Specifically, the below-B bundle of CDS is obtained by keeping only the CDS contracts in CDX.NA.HY

\footnotetext{
${ }^{9} \mathrm{~A}$ CDS is an over-the-counter (OTC) contract that seeks to provide insurance against the risk of a credit event, like failure to pay, on a given security. As such, for some corporate bonds, the corresponding CDS may be highly illiquid.

10 The most recent roll is referred to as "on the run".

${ }^{11}$ For more detail see: https://ihsmarkit.com/products/markit-cdx.html.

${ }^{12}$ Specifically, the set of contacts in CDX.NA.IG, minus the set of contracts in CDX.NA.IG.BBB.
} 
that are not included in CDX.NA.HY.BB and CDX.NA.HY.B. Finally, to calculate a credit risk spread for each ETF, we compute the weighted average of the spreads of these partitioned CDX indices, corresponding to different rating categories, with weights determined by the ETF's exposure to each rating category (i.e., the shares of the ETF's underlying portfolio invested in above-BBB, BBB, BB, B, and below-B bonds). The ETF-level credit risk spread is obtained at daily frequency.

Our approach implicitly assumes that sectoral compositions are similar between rating buckets of each ETF's portfolio and rating buckets determined by the new CDS bundles we construct from the CDX indices. More specifically, since the effects of the COVID-19 pandemic on credit risk do not seem to be homogeneous - some sectors, like energy, have been hit much harder than others - bundles that hold a significant portion of energysector CDS are more likely to see a large increase in the price of default protection. For example, our below-B CDS bundle holds a relatively large amount of energy-sector CDS compared to the other rating categories. Thus, if an ETF in our universe were to hold below-B-rated bonds that are not in the energy sector, our measure of credit risk may overstate that ETF's credit risk.

Further, similarly to Flannery et al (2017) we use ETF premiums/discounts, that is, the positive/negative discrepancy between the ETF price and its NAV, to measure real-time corporate bond liquidity, as when underlying holdings are traded less frequently, or not at all, ETF's prices tend to trade above or below the benchmark they are designed to track. The rationale is the following. Big investors known as "authorized participants" (AP) can swap a basket of the fund's underlying holdings for ETF shares - or vice versa. This process helps arbitrage away significant gaps between the ETF's share price and its NAV. But when the underlying holdings are costly to trade and illiquid, AP are less willing to arbitrage away these discrepancies. This implies that the gaps between an ETF's share price and its NAV can be used to proxy the arbitrage cost of trading the underlying bonds and their liquidity. Similarly, if investors stampede out of ETFs, given the relative illiquidity of many of the underlying bonds, the ETFs could start trading at significant discounts to NAV. Indeed, Flannery et al (2017) show that the absolute deviation of an ETF's traded price from its NAV, scaled by the average of the ETF and NAV prices is positively and significantly correlated with all the most commonly-used measures of individual bond liquidity.

Finally our measure of corporate bond issuance is obtained from Bloomberg at weekly frequency, which is important to be able to observe the speed at which the Fed's announcements of the credit facilities restart the frozen corporate debt market. In particular, for IG and HY bonds, we collect the issuance of dollar denominated bonds, issued domestically and globally (including Yankee bonds), and we exclude CDs, bonds with have a variable interest redemption, or that have a retained deal, as well as convertible. Then we also restrict our attention to those issued only in the U.S. and with at most five-year maturity to closely match the $\mathrm{P}(\mathrm{S}) \mathrm{MCCF}$ eligibility criteria.

\section{Results}

\subsection{Price reaction}


We start with analyzing the impact of the March 23 and April 9 announcements on the prices of IG and HY ETFs ordered by their underlying holdings of IG bonds, shown in Figure 1. Since both announcements were early in the morning, before the opening of ETF trading, each panel reports the percentage price changes from the end of the day before the announcement to $10 \mathrm{a}$.m. (ET) on the day of the announcement, that is, 30 minutes after market opening. Our hypothesis is that, if the Fed's credit facilities are the main factor driving price changes in these time windows, then we should observe larger price increases for the ETFs with larger shares of eligible IG bonds and their closest substitutes, that is, the so called "fallen angels"-corporate bonds that were rated IG and were subsequently downgraded to no lower than $\mathrm{BB}$.

Panel A shows that, fully-eligible ETFs focused on eligible IG corporate bonds registered an average return of 5.2\% in the time window around the March 23 announcement. This measures the joint impact of expected purchases of the ETFs and their underlying bonds, thus is probably an upper bound of the effect on IG bond returns. In contrast, ineligible ETFs focused on $\mathrm{HY}$ corporate bonds registered an average return of $0 \%$, in line with our hypothesis. Panel B shows that, following the April 9 announcement, there was a positive price response across nearly all ETFs in our sample. However, due to the new component of the announcement, the changes were greater for the newly-eligible HY ETFs, which registered an average return of about 5.2\%, than for the already eligible IG ETFs, which registered an average return of about $2.6 \%$. We believe that this additional increase in the price of fully-eligible ETFs is due to the larger-than-expected size of the program (which went from a maximum of $\$ 200$ to $\$ 750$ billion), therefore we estimate that the total effect of the two announcements on the IG bonds can be as high as $7.8 \%$ (i.e., $5.2 \%$ on March $23^{\text {rd }}$ plus $2.6 \%$ on April $\left.9^{\text {th }}\right)$.

Figure 2 digs a bit deeper in the reaction of the HY ETFs to analyze whether and how the reaction of the bond-eligible HY ETFs (i.e., ETFs not eligible for purchase but holding positive amounts of eligible IG bonds and fallen angels) differs from the reaction of the completely ineligible HY ETFs on March $23^{\text {rd }}$. Panel A shows the high-frequency returns of bond-eligible HY ETFs ordered by their cumulative holdings of BBB- and BB-rated corporate bonds (conditional on the ETF having some holdings in IG bonds). It can be observed that the two ETFs with the largest share of such bonds, which happens to be ETFs specialized in fallen angels, experienced an average return of about $3 \%$, while the average return among all bond-eligible ETFs is of about 1\%. Panel B indicates instead that the ineligible HY ETFs (i.e., those with no holdings of IG bonds) are those that registered on average a return equal to $0 \%$ following the March 23 announcement.

Figure 3 illustrates the same type of analysis as in Figure 2 but for the April 9 announcement. Panel A shows that the returns of newly-eligible ETFs with the largest holdings of BB-rated bonds, which are again the ETFs specialized in fallen angels, registered an average return of about $7.1 \%$, while the average return among all newlyeligible HY ETFs was of about 5.7\%. Finally, Panel B reports that among the neweligible HY ETFs that were ineligible on March $23^{\text {rd }}$ the average return is a bit lower, about $5.2 \%$. 
The overall message of Figures 1 to 3 seems to confirm our hypothesis, as the ETF returns clearly depend on the underlying holdings of eligible corporate bonds, suggesting that the $\mathrm{P}(\mathrm{S}) \mathrm{MCCF}$ is the main factor driving the ETF price responses. As summarized in Table 1, the returns of fully-eligible IG ETFs increased by about $7.8 \%$ in total across the two announcements. The bond-eligible HY ETFs focused on fallen angels (i.e., with at least $80 \%$ of their holdings in BBB- and BB-rated bonds) registered a cumulative return of about $10.1 \%$ (3\% on March $23^{\text {rd }}$ and an additional $7.1 \%$ on April $9^{\text {th }}$ when they became newly-eligible), indicating that fallen angels are expected to benefit more than IG bonds from future Fed purchases. Further, the inclusion of recent fallen angels in the $\mathrm{P}(\mathrm{S}) \mathrm{MCCF}$ might have put a floor on the ensuing damage to BBB-rated bonds, pushing investors to overweight portfolio allocations toward these securities. In contrast, all the other bond-eligible HY ETFs that became newly eligible on April $9^{\text {th }}$ registered an average cumulative return of about $6.7 \%$ (1\% on March $23^{\text {rd }}$ and an additional $5.7 \%$ on April $\left.9^{\text {th }}\right)$. Finally, the ineligible HY ETFs that became newly eligible on April $9^{\text {th }}$, characterized by zero holdings of IG bonds and relatively smaller shares of BB-rated bonds, registered an average cumulative return of about 5.2\% $\left(0 \%\right.$ on March $23^{\text {rd }}$ and $5.2 \%$ on April $\left.9^{\text {th }}\right)$. This last value is a good measure of the upper bound of the impact on HY corporate bonds.

Table 1: Average returns in the small time window around the announcements.

\begin{tabular}{|l|l|l|l|l|}
\hline $\begin{array}{l}\text { Average } \\
\text { Returns }\end{array}$ & $\begin{array}{l}\text { IG ETFs } \\
\text { (IG Bonds only) }\end{array}$ & $\begin{array}{l}\text { Fallen Angels } \\
(\mathrm{IG}+\mathrm{BB} \geq 80 \%)\end{array}$ & $\begin{array}{l}\text { HY ETFs } \\
(\mathrm{BB}+\mathrm{IG} \geq 20 \%)\end{array}$ & $\begin{array}{l}\text { HY ETFs } \\
(\text { no IG bonds) }\end{array}$ \\
\hline March 23 & $5.2 \%$ & $3.0 \%$ & $1.0 \%$ & $0.0 \%$ \\
April 9 & $2.6 \%$ & $7.1 \%$ & $5.7 \%$ & $5.2 \%$ \\
\hline Total & $7.8 \%$ & $10.1 \%$ & $6.7 \%$ & $5.2 \%$ \\
\hline
\end{tabular}

In summary, if in Table 1 we focus only on the average ETFs returns observed in response to the March 23 announcement, when eligibility was restricted to IG bonds, it is evident that the magnitude of the returns is an increasing function of the degree of eligibility. The higher the share of IG bonds and their closest substitutes in the ETF's underlying portfolio, the higher the return realized in the small time window around the announcement. The message is similar if we focus on the average ETFs returns observed in reaction to the April 9 announcement, which lowered the eligibility threshold to recently downgraded IG bonds with ratings no lower than BB. In Table 1, it is possible to note that, among the newly-eligible HY ETFs, the larger the share of fallen angels and their closest substitutes (BB bonds) in the ETFs' portfolio, the larger the average realized return. This confirms again that the degree of eligibility matters, as a larger share of eligible bonds implies a higher likelihood of being affected by the Fed's future purchases.

Finally, if on April $9^{\text {th }}$, because of the exclusion of bonds issued by depository institutions or depository institution holding companies, we restrict our attention to the reaction of IG ETFs ordered by their shares of financial bonds (not shown), we find that at the low end of the distribution (i.e., financial sector holdings between $1 \%$ and $17 \%$ ) the average return is about 4\%; while, at the high end of the distribution (i.e., financial sector holdings between $45 \%$ and $60 \%$ ) the average return is about a $0.6 \%$. That is, the IG ETFs with the lowest share of ineligible financial bonds performed significantly better, 
suggesting in turn that non-financial corporate bonds performed significantly better. This is consistent with the previous findings showing that the eligibility of the underlying bonds is the most important factor driving the price reaction.

However, it is worth noting that when we order the universe of IG and HY ETFs by the average maturity of their underlying bond holdings, as the Fed indicated that purchases will be limited to corporate bonds with a maturity of five years or less, we do not observe any significant difference in the price responses across ETFs. This might indicate that the maturity of the underlying bonds does not play a big role because even if the Fed will not buy long-dated corporate bonds, it will buy shares of ETFs that hold long-dated corporate bonds, implying that the Fed is indirectly buying long-dated corporate bonds through someone else. However, in our sample, the average maturity of IG ETFs' holdings is about 7.2 years, while the average maturity of HY ETFs' holdings is about 4.4 years, which are not very far from the longest maturities eligible for purchase. Nevertheless, the design of the $\mathrm{P}(\mathrm{S}) \mathrm{MCCF}$ might allow ETFs and their arbitrageurs to transmit quickly the effects of future purchases to some of the ineligible corporate bonds, along dimensions and to the extent deemed appropriate by those market participants.

\subsection{Credit Risk}

Next, we examine the impact of the announcements on various proxies of credit risk at the ETF level. The first proxy is extremely simple, as for each ETF it is obtained as the weighted average of the IG CDX spread and the HY CDX spread at 5-year maturity, with weights equal to the shares of the ETF's underlying portfolio invested in IG and HY bonds, respectively. This credit risk proxy has the great advantage of being available at intraday frequency, therefore, similar to the analysis of ETF prices, we can focus on credit risk changes in the small time windows around the announcements. Figure 4 shows the intraday changes in the credit risk proxies for all ETFs ordered by their underlying holdings of IG bonds. Obviously, in the case of HY ETFs with no holding of IG bonds, the credit risk proxy will simply equal the change in the HY CDX spread.

Panel A indicates that, in response to the March 23 announcement, the credit risk of ETFs with IG holdings (i.e., either fully-eligible or bond-eligible ETFs) declined on average by 23 basis points, while the credit risk of ineligible ETFs declined on average by about 15 basis points. The decline in the CDX spreads for both IG and HY bonds shows that the announcement of the credit facilities did have an effect on perceptions of default risk. This is in line with the evidence reported in Nozawa and Qiuy (2020). However, it should be noted that, while the IG CDX index ended the day even lower ( -25 basis points), the HY CDX index retraced the initial decline and ended the day with a net increase of about 27 basis points, therefore in the case of $\mathrm{HY}$ bonds the reduction in perceived credit risk was short lived. Panel B indicates that in response to the April 9 announcement, the credit risk of ETFs with IG holdings declined on average by 47 basis points, while the credit risk of the newly-eligible HY ETFs declined on average by about 125 basis points, indicating that the expansion of the eligibility criteria was viewed as particular beneficial to the HY corporate bond market. These changes clearly capture a significant improvement in perceptions of default risk. In particular, the drastic drop in the HY CDX spread could reflect three possibilities: (1) a lower probability that fallen angels will create dysfunction in the HY market, which should help to ensure that HY firms will be able to continue to issue debt in the future; (2) investors seeing the April 9 
announcement as raising the probability that the Fed will eventually buy legacy HY debt too; and (3) a spillover from firms whose bonds will be purchased to broader credit markets, perhaps through an improvement in macro conditions. However, the last hypothesis seems less likely considering various available forecasts of the economic damages related to the covid-19 crisis.

We now turn to our more granular proxy of credit risk, which accounts for each ETF's risk exposure to the various rating categories and, as described in Section 5, is obtained from the spreads of various CDS bundles. Recall that we were able to construct this measure at daily rather than intraday frequency. Figure 5 shows the daily changes in the credit risk proxies of all ETFs ordered again by their underlying IG holdings. In contrast to Figure 4, Panel A indicate that, following the March 23 announcement, there was no improvement in perceived credit risk. In particular, the uptick in the credit risk measures of eligible IG ETFs is due to their exposure to the BBB rating category. As shown in Table 2, the average CDS spread of the BBB-rated bundle increased a bit, while that one of the above-BBB bundle edged down. But, we believe that such uptick is mostly due to worsening liquidity in the CDS market, as shown by the widening of the CDX-CDS basis on March $23^{\text {rd }}$, reported in the last two columns of Table 2. In the case of the ineligible ETFs, the picture is grimmer, as all HY ETFs experienced a jump in their credit risk spreads, which were on average 267 basis points higher, mostly driven by the poor performance of the CDS bundle focused on the below-B rating category (as shown in Table 2 the average spread in this bundle increased by about 2000 basis points). This suggests a significant deterioration in the perceptions of default risk for HY corporate bonds, as the exclusion of these bonds from the credit facilities clearly worsened credit prospects for lower-quality HY issuers.

Table 2: Daily Changes in Proxies of Credit Risk and CDS liquidity (CDX-CDS basis)

\begin{tabular}{llccccc}
\hline & \multicolumn{2}{l}{ CDS Average Change } & CDX Change & \multicolumn{2}{c}{ CDX-CDS Basis Change } \\
& Mar 20-23 & Apr 8-9 & Mar 20-23 & Apr 8-9 & Mar 20-23 & Apr 8-9 \\
\hline IG & $\mathbf{2 . 2}$ & $\mathbf{- 1 9 . 3}$ & $\mathbf{- 2 5}$ & $\mathbf{- 2 3}$ & $\mathbf{2 7 . 1}$ & $\mathbf{3 . 7}$ \\
Above-BBB & -1.5 & -14.2 & & & & \\
BBB & 4.0 & -21.8 & & & & \\
BB & $\mathbf{3 8}$ & $\mathbf{- 9 0 . 3}$ & $\mathbf{2 0 . 3}$ & $\mathbf{- 9 9}$ & $\mathbf{1 7 . 8}$ & $\mathbf{8 . 8}$ \\
B & 9.0 & -122 & & & & \\
Below-B & 2002 & -886 & & & & \\
HY & $\mathbf{2 6 7}$ & $\mathbf{- 1 9 3}$ & $\mathbf{2 7 . 2}$ & $\mathbf{- 9 4}$ & $\mathbf{2 3 9 . 7}$ & $\mathbf{- 9 9 . 3}$ \\
\hline
\end{tabular}

However, as reported in Table 2, the large discrepancy between the daily change in the HY CDX spread (+27 basis points) and the daily change in the average spreads of the CDS bundles corresponding to the $\mathrm{BB}, \mathrm{B}$, and below-B rating categories $(+267$ basis points) indicates a notable widening of the CDX-CDS basis, and hence a significant deterioration in the liquidity of the HY CDS market on the day of the announcement. This, in turn, suggests that the overall variation in our proxy of credit risk on March $23^{\text {rd }}$ should be taken with a grain of salt, as changes in the liquidity of CDS contracts cloud our reading of credit risk. But this does not appear to be the case for the second announcement. Similar to Figure 4, Panel B in Figure 5 confirms that on April $9^{\text {th }}$ there was indeed a widespread improvement in perceptions of default risk. The daily reduction 
in the more granular proxies of credit risk for all ETFs is quite similar in magnitude to the intraday decline in the IG and HY CDX spreads, respectively. For example, as shown in Table 2, our proxy indicates that on April $9^{\text {th }}$ the perceived credit risk in the BB-rated bundle declined by about 90 basis points, while the BB CDX spread declined by 99 basis points, indicating that the CDX-CDS basis widened by just 9 basis points. In other words, the increase in CDS liquidity risk is very small compared to the overall decline in the credit risk measure, suggesting that, for the second announcement, we can trust our ETFlevel proxy of credit risk. However, for the lowest-rated category, the improvement in credit risk might be overstated. The CDX-CDS basis corresponding to the below-B bundle declined a lot, accounting for about half of the reduction in our credit risk proxy (shown in Table 2). But, since we are interested in the relative differences in ETF credit risk rather than in the overall change in credit risk, the variation in the CDX-CDS basis should not be very worrisome.

Our next step consists of understanding whether changes in perceived credit risk are the main factor driving variations in ETF prices on the days of the announcements. To this purpose, Figure 6 plots the ETFs' intraday price changes as function of the ETFs' daily changes in underlying credit risk. ${ }^{13}$ By analyzing panel $\mathrm{A}$ and $\mathrm{B}$, it is easy to note that there is no clear relation between the magnitude of the change in price and the magnitude of the change in credit risk. In particular, within the IG and HY categories, respectively, the change in price seems disconnected from the change in CDX spread. The only notable patterns are again the relative differences between the returns of the fully-eligible IG ETFs and the ineligible HY ETFs on March $23^{\text {rd }}$, as well as the relative differences between the returns of the newly-eligible HY ETFs and the already-eligible IG ETFs on April $9^{\text {th }}$. To verify this analytically, we estimate the following cross-sectional regression, using all 87 ETFs:

$$
\operatorname{Return}_{i, t}=\alpha+\beta_{1} \Delta C D X_{i, t}+\beta_{2} I G+\varepsilon_{i, t}
$$

where Return $_{i, t}$ is the intraday return of each $\operatorname{ETF}(i)$ on announcement day $t, \Delta C D X_{i, t}$ is the daily change in our proxy of credit risk, and $I G$ is a dummy variable taking the value of 1 if the ETF is in the investment-grade category and zero otherwise.

Table 3: Estimates of the Relation between Returns and Credit Risk and Eligibility.

\begin{tabular}{|l|l|l|l|}
\hline March $23^{\text {rd }}$ & Coefficients & t-stats & Adj. R-squared \\
\hline Constant & 0.62 & 0.66 & 0.62 \\
Beta(1) & -0.0007 & -0.26 & \\
Beta (2) & 5.87 & 6.10 & \\
\hline April 9 & & & 0.55 \\
\hline Constant & 4.33 & 4.21 & \\
Beta(1) & -0.005 & -1.13 & \\
Beta (2) & -2.79 & -2.97 & \\
\hline
\end{tabular}

\footnotetext{
${ }^{13}$ We chose to display the intraday price reaction rather than the daily price reaction, which would better match the frequency of the credit risk proxy, because the message is identical and to have some consistency with Figure 1.
} 
If our interpretation of Figure 6 is correct, we should find that $\beta_{1}$ is not statistically significant, indicating that the change in perceived credit risk is not the factor driving the price changes on the day of the announcement, $\beta_{2}$ is positive and significant on March $23^{\text {rd }}$, as only IG bonds were eligible, and $\beta_{2}$ is negative and significant on April $9^{\text {th }}$ when HY ETFs and fallen angels became eligible, as on that day IG ETFs perform significantly worse than HY ETFs. This is precisely what we find as shown in Table 3.

This would suggest that the large and positive price reaction among the fully-eligible, bond-eligible, and newly-eligible ETFs across the two announcements is driven by the elimination of "the worst case scenario," that is, a credible reduction in the risk of an abrupt credit crunch for eligible issuers. In other words, the unprecedented scope and speed of the Fed's response in credit markets might have represented to investors a "“whatever it takes' moment, but backed by actions," as wittily described by Roberto Perli, a partner at Cornerstone Macro and former Fed economist. Further, the expansion of the eligibility criteria on April $9^{\text {th }}$ might have been interpreted by market participants as increased flexibility in the Fed's willingness and ability to directly support corporate debt markets, spurring investors to believe that in the future the Fed might be willing to broaden its safety net.

\subsection{Liquidity Risk and Persistence of Announcement Effects}

Before concluding that the announcement effects are driven by the elimination of "disaster risk," we have to check whether ETF prices are driven by other factors, such as an improvement in corporate bond liquidity. Therefore, we analyze on the days of the announcements fluctuations in ETF premiums/discounts, as those are often used to proxy real-time corporate bond liquidity. Figure 7 displays both the levels and changes of ETFs' daily premiums/discounts ordered by ETFs' underlying IG holdings. Within each panel, the top graph shows the levels of the ETF premium/discount on the day before and of the announcement, as we believe it is important to understand the direction of the discrepancy between the ETF's price and its NAV before computing the changes, which are displayed in the bottom graph.

Panel A indicates that on March $20^{\text {th }}$, the day before the first announcement, every ETF in our sample was trading at a large discount relative to the fund's underlying NAV. This is not surprising as all ETFs were experiencing outflows in the first half of March, so their prices were declining faster than their NAV, as the underlying securities were hardly trading. By the end of the day on March $23^{\text {rd }}$, every IG ETF either almost completely reduced its discount, or flipped from a discount to a small premium, with an average change of about $4.4 \%$. In contrast, the improvement among ineligible HY ETFs is less noticeable (about $0.8 \%$ on average), as nearly all of them continued to trade at a discount relative to their NAV following the announcement. Overall, this picture suggests some improvement in the liquidity of the underlying IG corporate bonds, which being eligible for purchase would benefit from the increased trading opportunities with a large investor like the Fed. Panel B instead leads to a somewhat mixed conclusion. On April 8, the day before the second announcement, except for two HY ETFs, all ETFs in our sample were trading at a premium relative to their NAV. Following the April 9 announcement, ETF premiums increased rather than decreasing, with those of the newly-eligible HY ETFs increasing by more than those of the already-eligible IG ETFs $(2.2 \%$ versus $1 \%$, 
respectively). This widening of already existing gaps between ETFs' prices and their NAV would be suggestive of a deterioration in the corporate bond liquidity, which however seems a bit counterintuitive given the positive reaction observed so far for the ETFs' price and credit risk on April 9.

For this reason we dig a bit more in the widening of those gaps, to better understand the timing and persistence of their fluctuations, whose time series are plotted in Figure 8. Specifically, the top panel plots separately the time series of the weighted average of the prices and NAVs of the three largest IG ETFs, and the bottom panel plots those time series for the three largest HY ETFs, with weights proportional to the size of each ETF. The rationale behind these figures is the following. Hao, Kim, Sul, and Wang (2019) argue that since investors are attracted to the ETF bond market because of its high liquidity and low price impact, it is possible that when a fundamental shock changes the value of the underlying security, the trading and price adjustments occur first in the ETF market and then the gap to the underlying bond market gets arbitraged away by the AP and other sophisticated investors. That is, price discovery occurs first in ETFs and then in the underlying bonds. To support this hypothesis those authors show that ETF returns predict its own NAV returns and aggregated ETF returns predict underlying bond returns. These results are also the main reason why we look at the ETF universe to understand the impact of the Fed credit facilities on the underlying corporate bonds. Importantly, Hao et al. (2019) findings imply that if we observe ETF prices to lead the NAV prices without reversal, and consequently we observe discrepancies between ETF prices and their NAV to open only temporarily in response to the Fed announcements, we should not necessarily conclude that bond market liquidity deteriorated. This is because these patterns can be observed when a fundamental shock changes the value of the underlying securities but is reflected faster in ETF prices, which seems to be the case for IG bonds both on March $23^{\text {rd }}$ and April $9^{\text {th }}$, and perhaps to a smaller extent for HY bonds.

Panel A shows that once the covid-19 crisis starts, IG ETF prices decline faster than the NAV, then they start increasing sharply ahead of and during the first announcement, while the NAV takes about a week to adjust to the new ETF price level. Similarly, ahead of and during the second announcement, IG ETF prices increase faster than the NAV, which takes about two weeks to catch up with the ETF price. This would indicate that what might look like a deterioration in bond liquidity during the announcement - the gap between ETF price and NAV widens - is just a reflection of a slower price discovery in the underlying IG bond market. Panel B depicts a somewhat different story for HY ETFs. First, HY ETF prices do not move ahead of the first announcement but only following the announcement, and while those prices do increase faster than the NAV, they tend to overshoot the NAV. Especially after the second announcement, the ETF prices retraced some of the initial gain, with the ETF price and NAV meeting half way after about a week. Further, after each announcement, once the gap between the ETF price and NAV is completely closed, the new fundamental value is significantly smaller than the initial jump triggered by the two announcements. Obviously, it is hard to know whether this is due to an overreaction to the announcements or to additional negative news hitting the HY bond market.

\subsection{Issuance}


Our final figure is focused on corporate bond issuance to verify whether the introduction of the $\mathrm{P}(\mathrm{S}) \mathrm{MCCF}$ restarted the frozen corporate debt market. Panel A of Figure 9 shows weekly issuance of dollar denominated bonds. It is evident that following the first announcement the IG debt market roared back, while the HY debt market got revived by the second announcement, which extended the eligibility to HY ETFs and recent fallen angels. Panel B, by restricting issuance to domestic bonds with at most 5 years to maturity, that is, those eligible for purchase by the $\mathrm{P}(\mathrm{S}) \mathrm{MCCF})$, shows that HY issuance was mostly concentrated in the segment eligible for purchase. This corroborates that the factor driving the improvement in the HY primary credit market is indeed the mere promise of the Fed's future purchases. Overall, April has seen record-level issuance of IG corporate bonds, which totaled more than $\$ 300$ billion, and the highest quality HY borrowers were able to get credit again. This type of reaction in primary credit markets is in line with what observed following previous corporate purchase programs by foreign central banks (see for example, D’Amico and Kaminska, 2019). Reportedly, some companies are now issuing cheaper long-term debt to repay the revolving lines of credit that they frantically drew down when the coronavirus first hit. At the time of the writing of this paper, according to Barron's estimates, some $\$ 14$ billion of credit lines has been repaid this way.

\section{Conclusions}

In summary, we have shown that in response to the announcements of the $\mathrm{P}(\mathrm{S}) \mathrm{MCCF}$ there has been a large and positive jump in the prices of directly-eligible bond ETFs as well as ETFs holding eligible bonds or their close substitutes. Further, following the second announcement, there has been a drastic drop in the perceptions of default risk. However, the magnitude of the price reactions does not seem directly related to the magnitude of the changes in proxies of credit risk and liquidity risk. The main factor driving the relative differences in ETF returns seems to be the underlying share of eligible bonds, that is, the ETF' degree of eligibility, which determines the likelihood of being affected by future purchases. This leads us to believe that those announcements worked primarily by eliminating "disaster risk" for eligible issuers, that is, the possibility of an abrupt credit crunch. Finally, we have also shown that the mere promise of a large buyer entering the primary and secondary credit markets has been sufficient to restart issuance in frozen debt markets, although this does not seem the case for the lowestquality borrowers.

In the future, once the $\mathrm{P}(\mathrm{S}) \mathrm{MCCF}$ purchases are completed, we will be able to better assess the longer-term effects of these programs and their transmission channels. In other words, similarly to D'Amico and King (2013) and D'Amico and Kaminska (2019), we hope to use bond-level data to estimate the stock effects of $\mathrm{CE}$ and compare them to those of QE in the U.S. 
Figure 1. ETFs' price reaction ordered by the share of IG bonds in their portfolios

Panel A: March 23

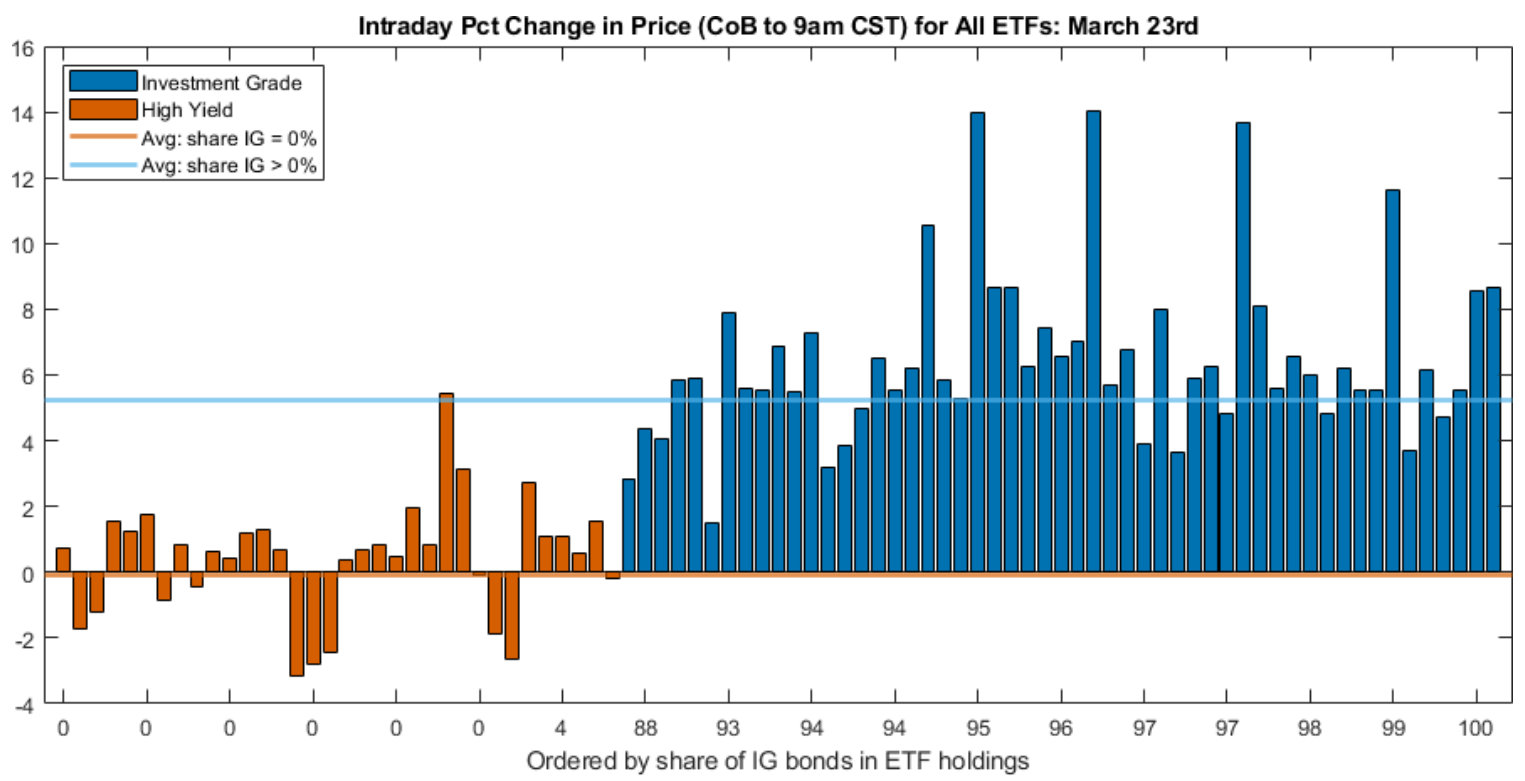

Panel B: April 9

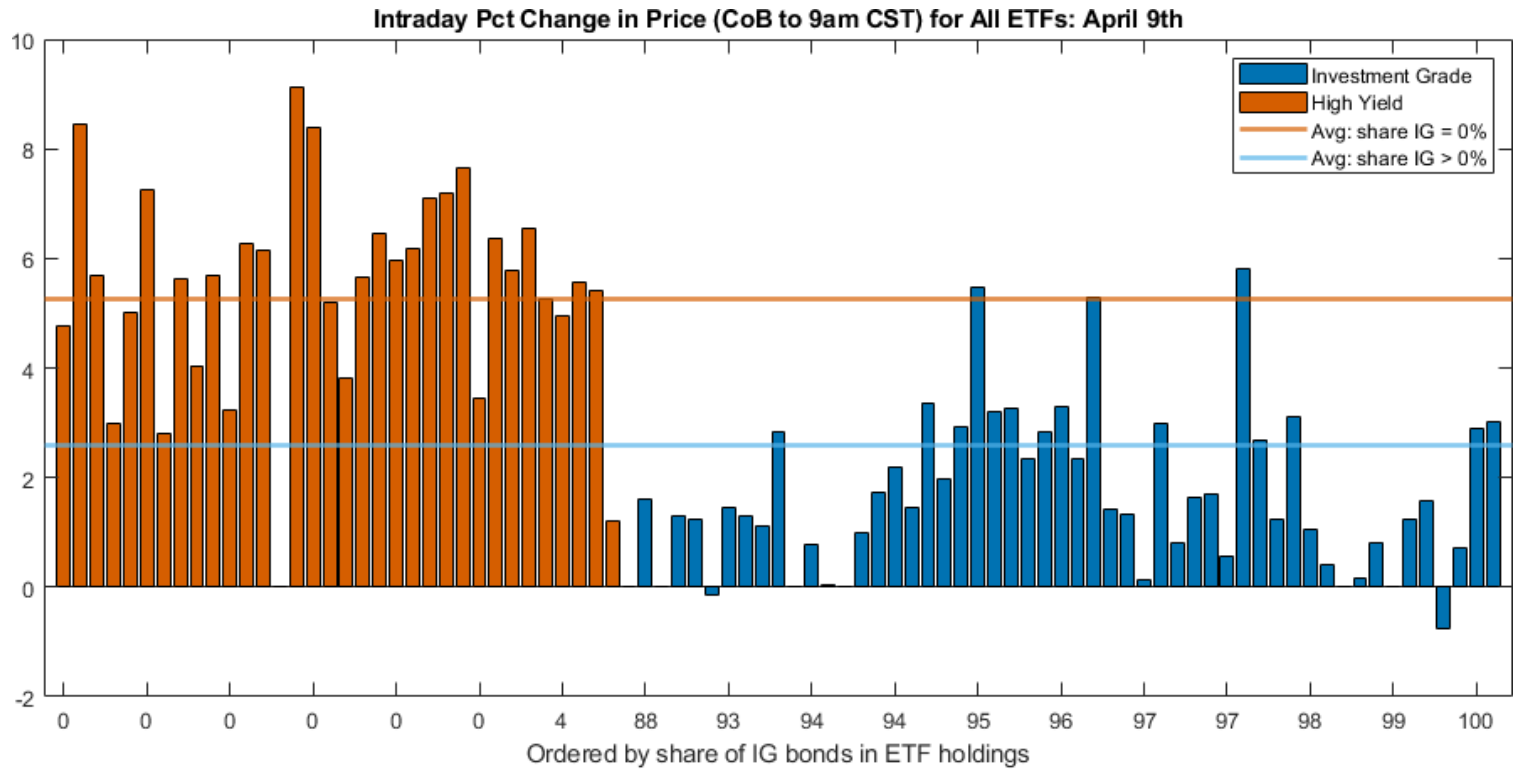


Figure 2: HY ETFs' price reaction to the March 23 announcement

Panel A: HY ETF with some positive holdings of IG bonds

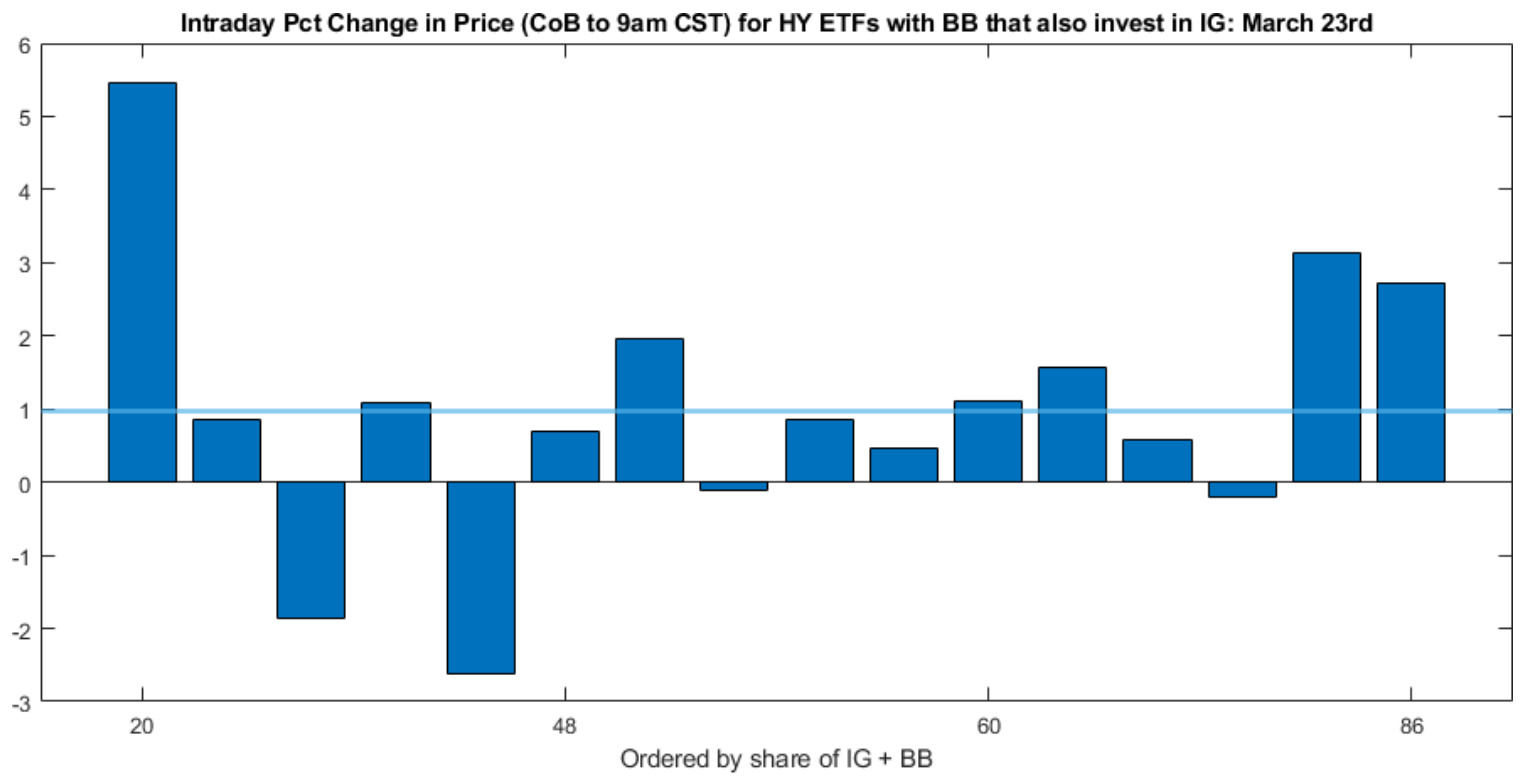

Panel B: HY ETF with no holdings of IG bonds

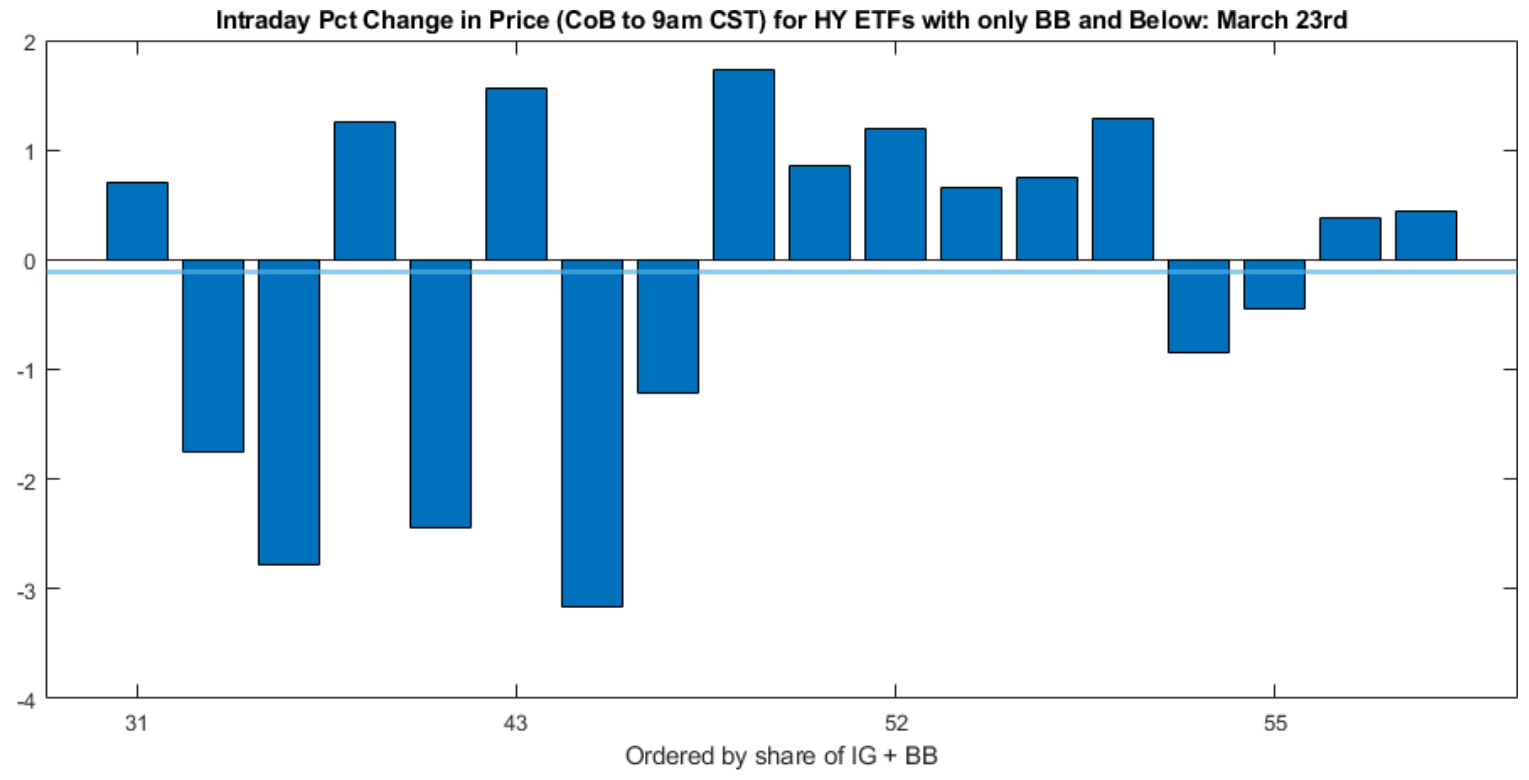


Figure 3: HY ETFs' price reaction to the April 9 announcement

Panel A: HY ETF with some positive holdings of IG bonds.

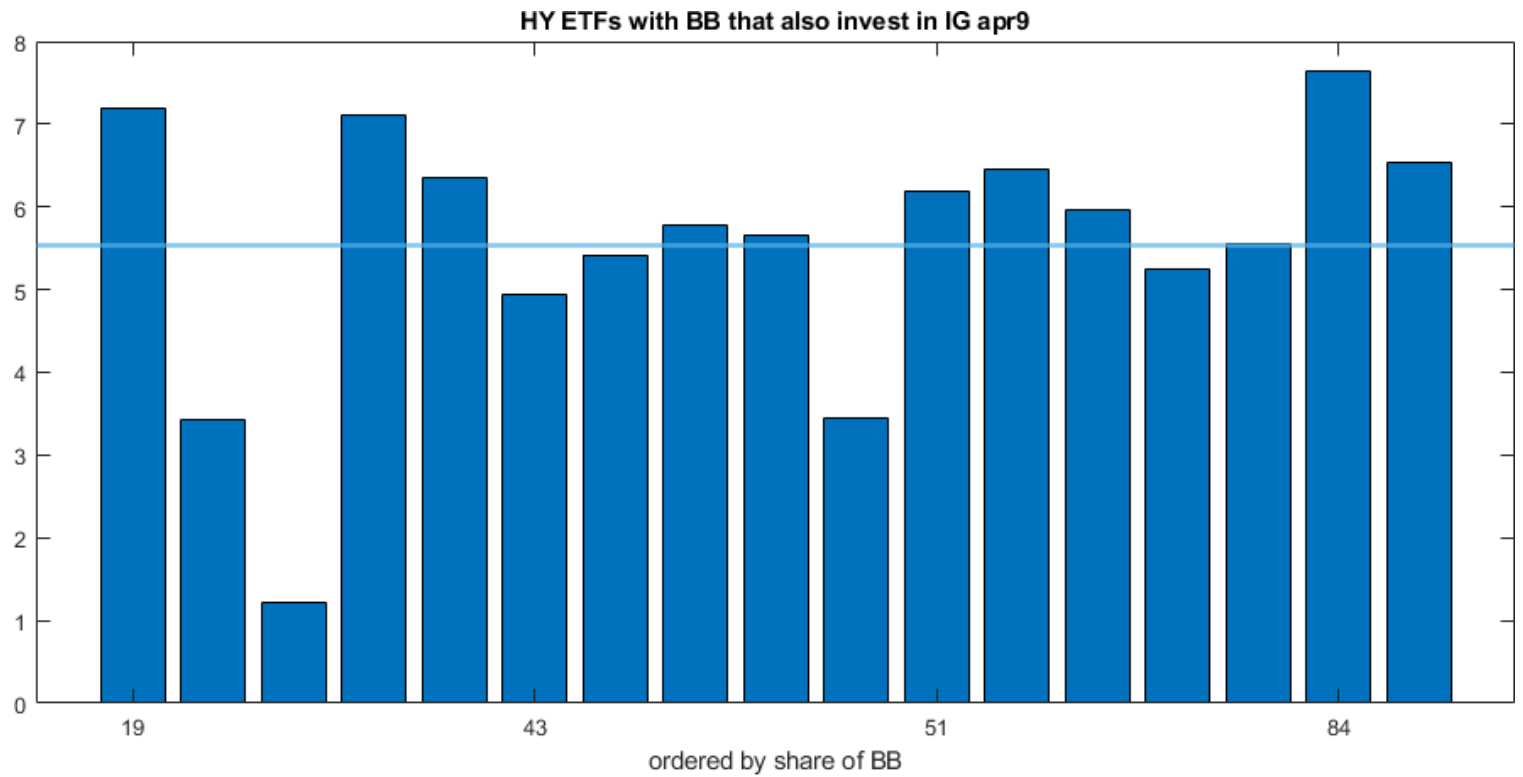

Panel B: HY ETF with no holdings of IG bonds

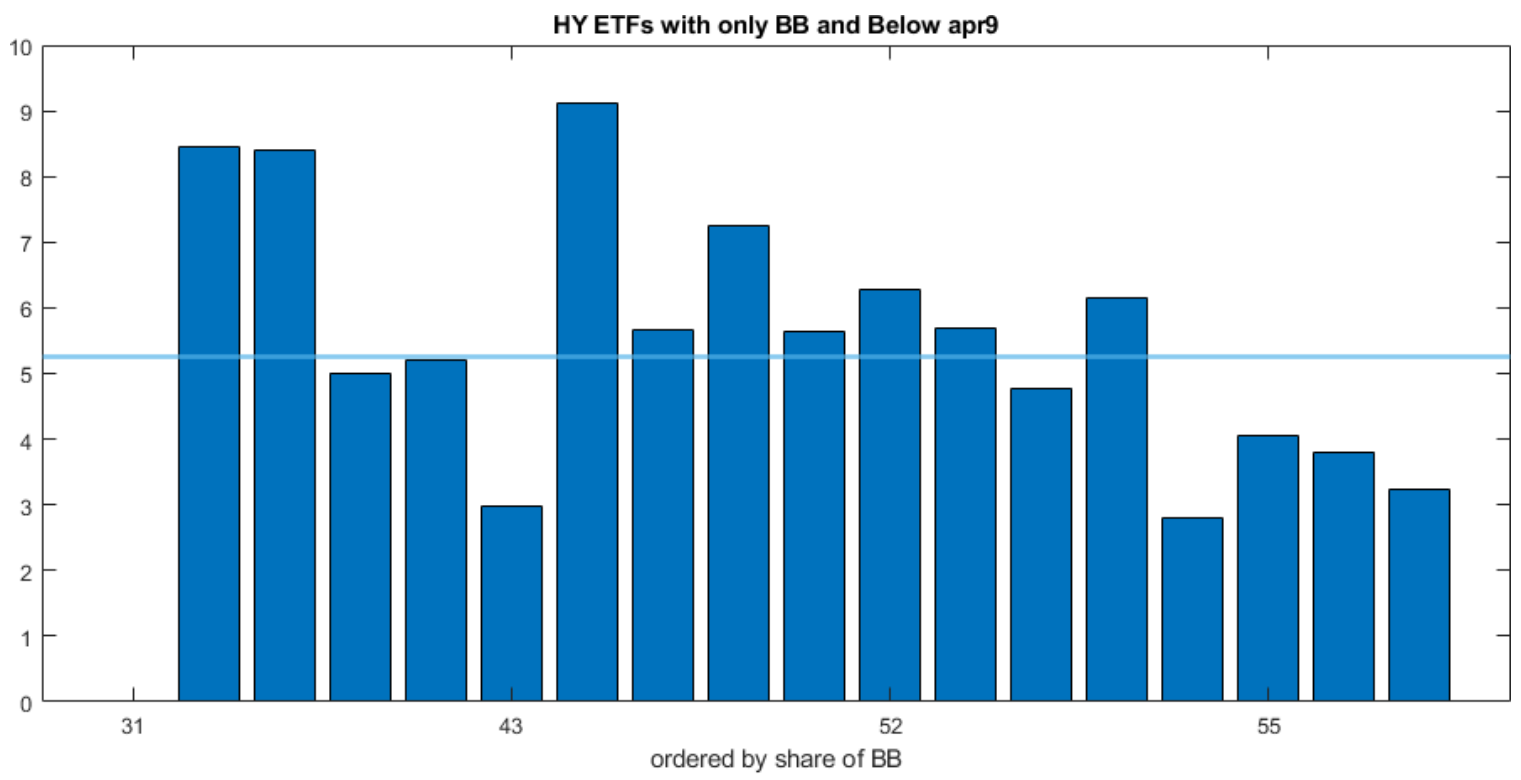


Figure 4: ETFs' intraday changes in the simple credit risk proxy ordered by the share of IG bonds

Panel A: March 23

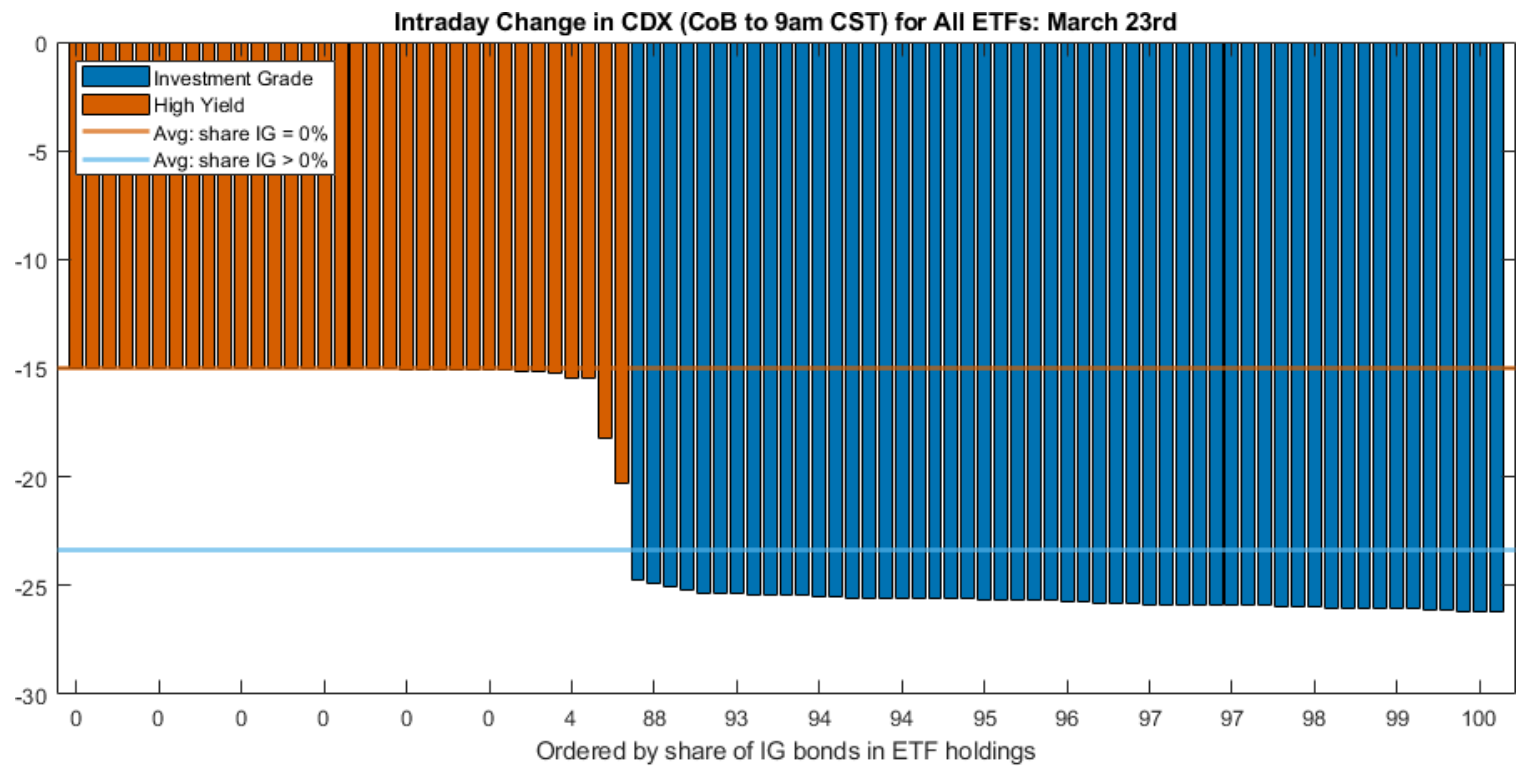

Panel B: April 9

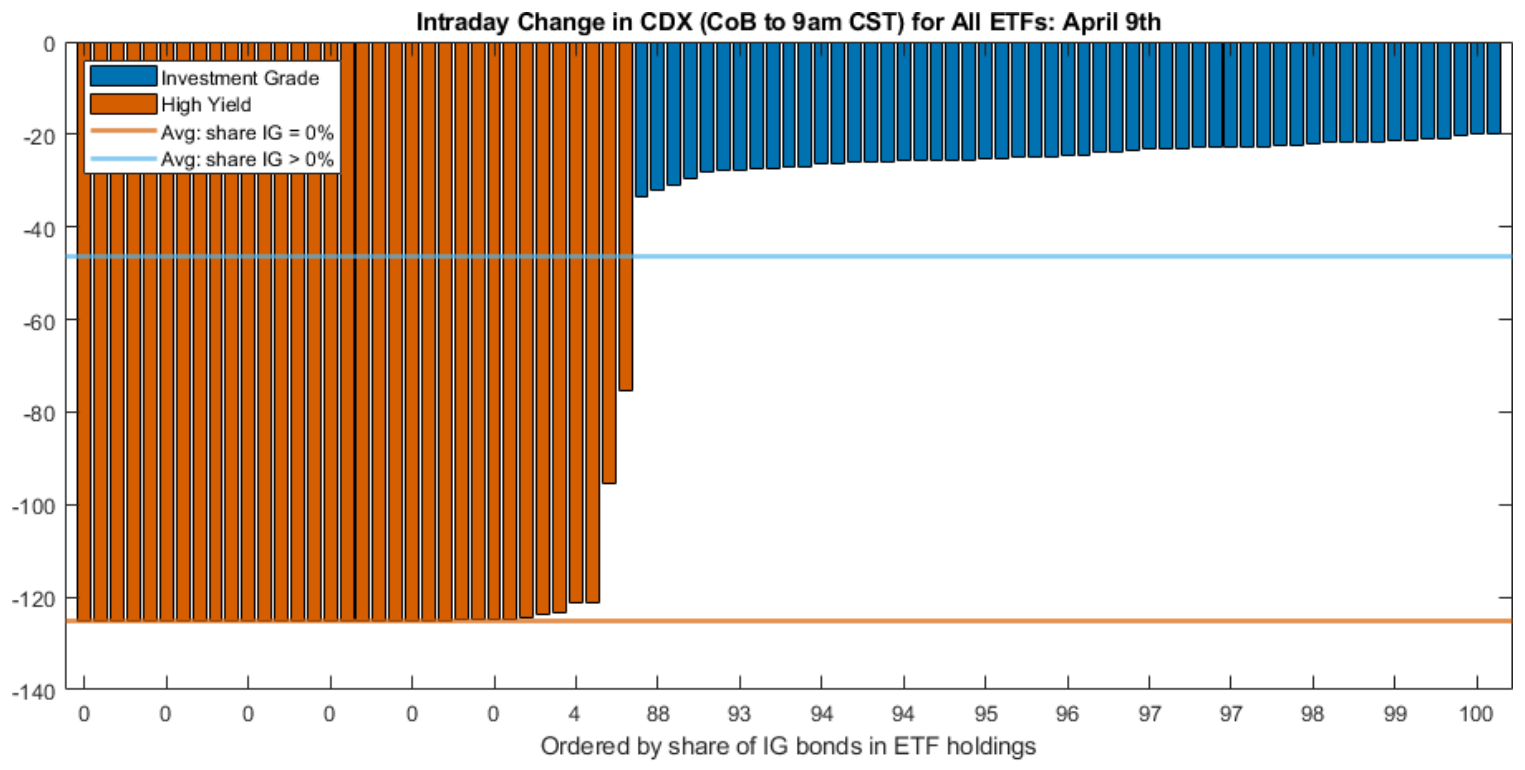


Figure 5: ETFs' daily changes in the more granular credit risk proxy ordered by the share of IG bonds

Panel A: March 23

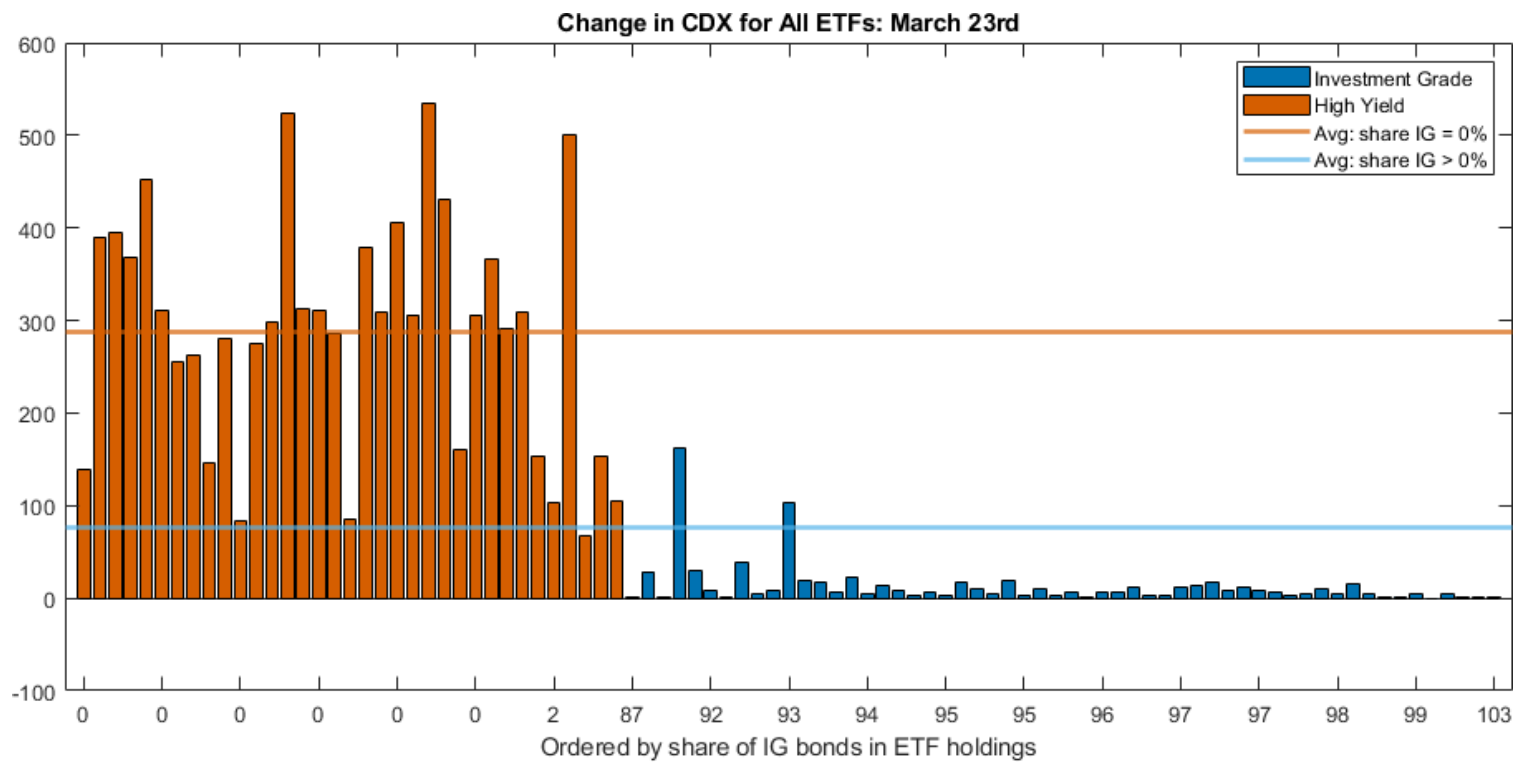

Panel B: April 9

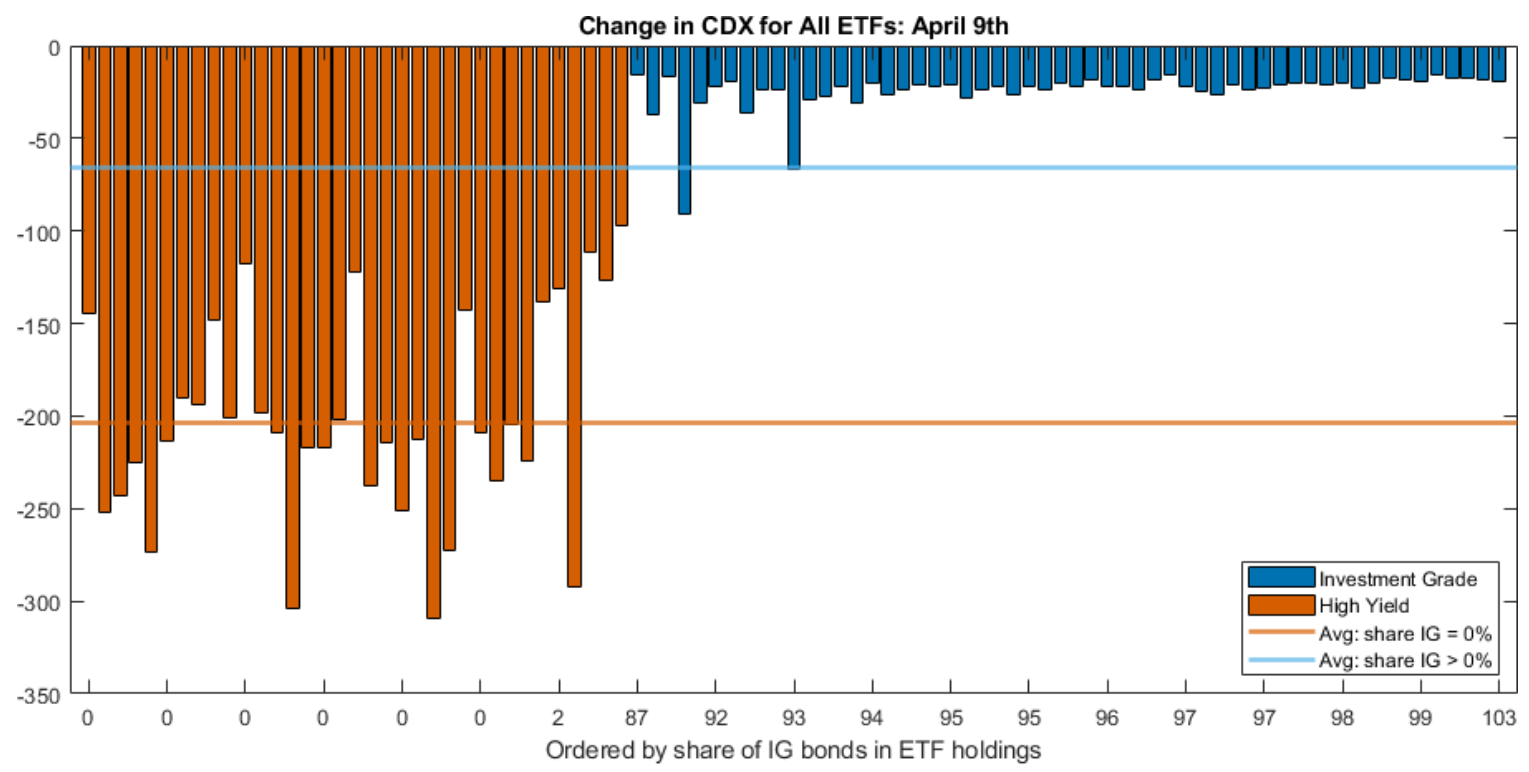


Figure 6. ETFs' intraday price reaction ordered by ETFs' daily changes in underlying credit risk.

Panel A: March 23

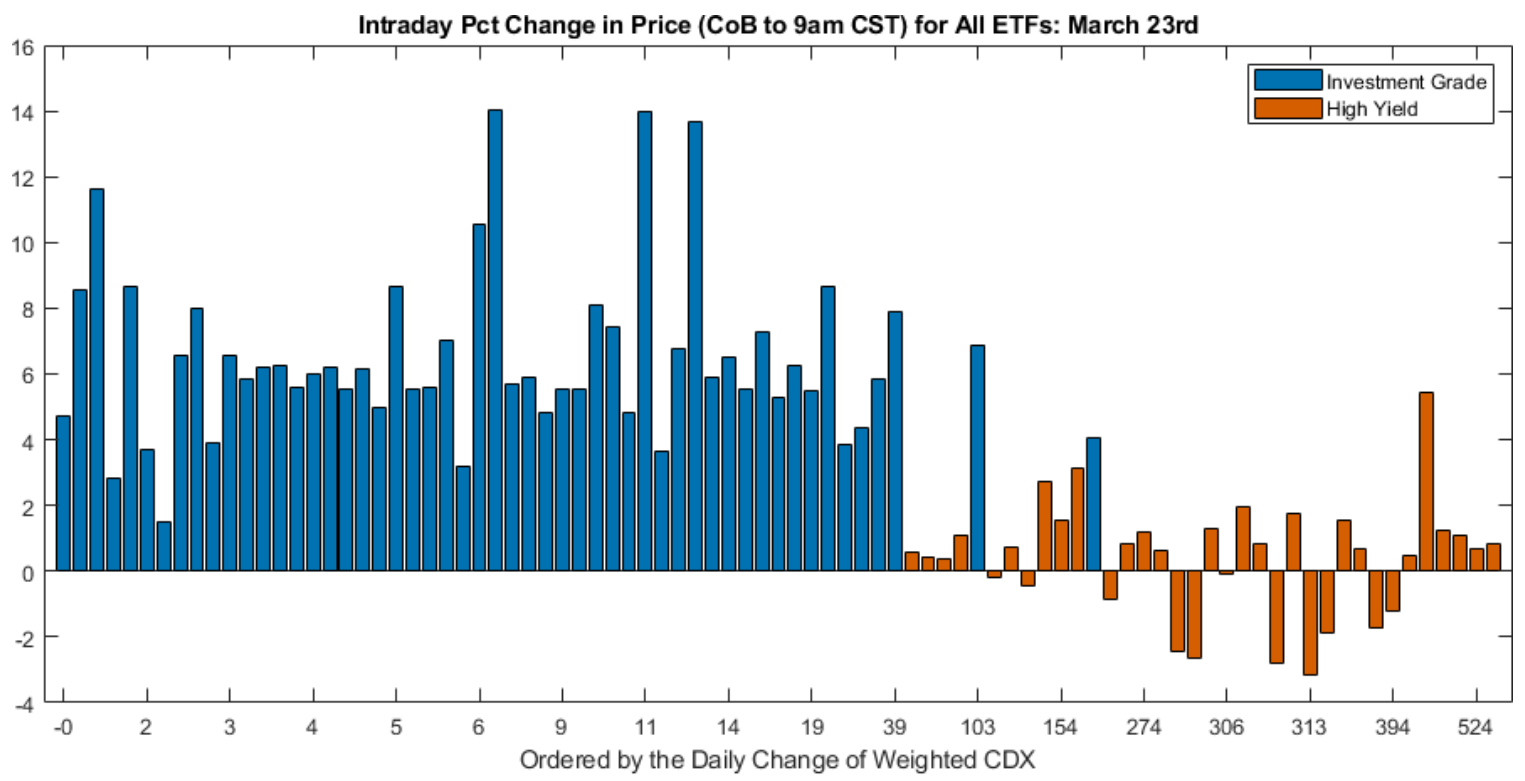

Panel B: April 9

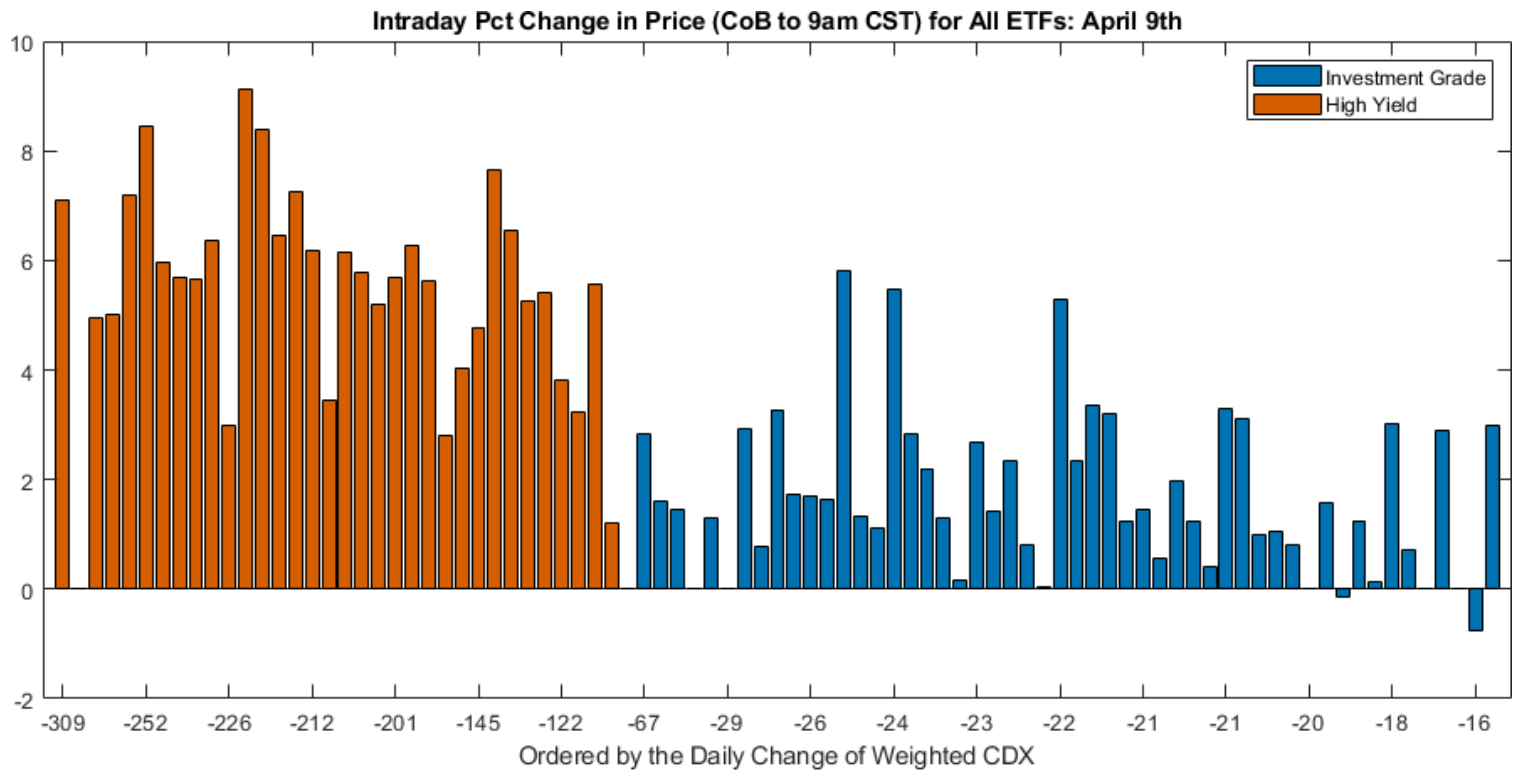


Figure 7: ETFs' daily changes in premium/discount ordered by the share of IG

Panel A, March 23 announcement, ETFs' Percent Premiums/Discounts
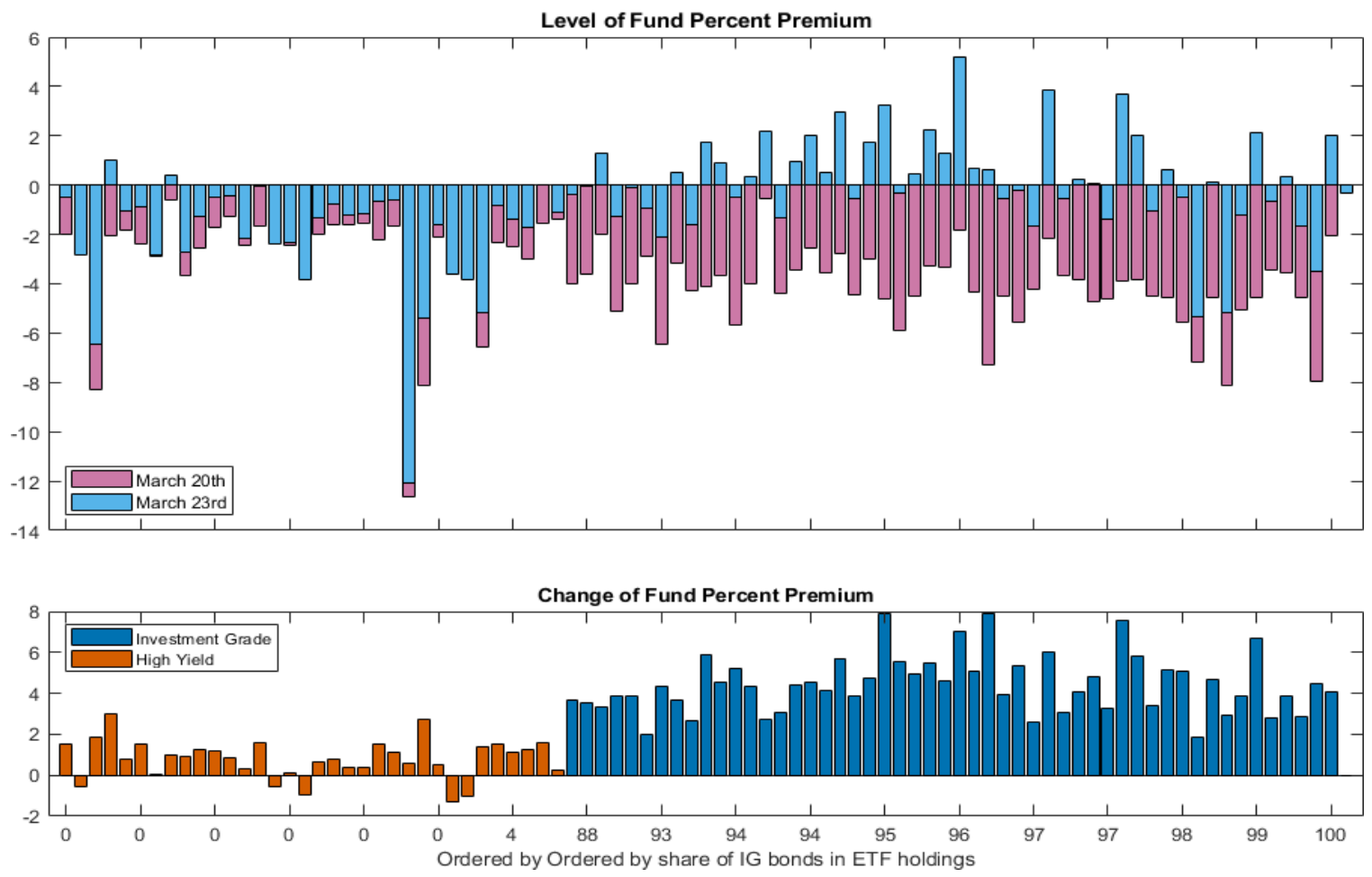

Panel B, April 9 announcement, ETFs' Percent Premiums/Discounts
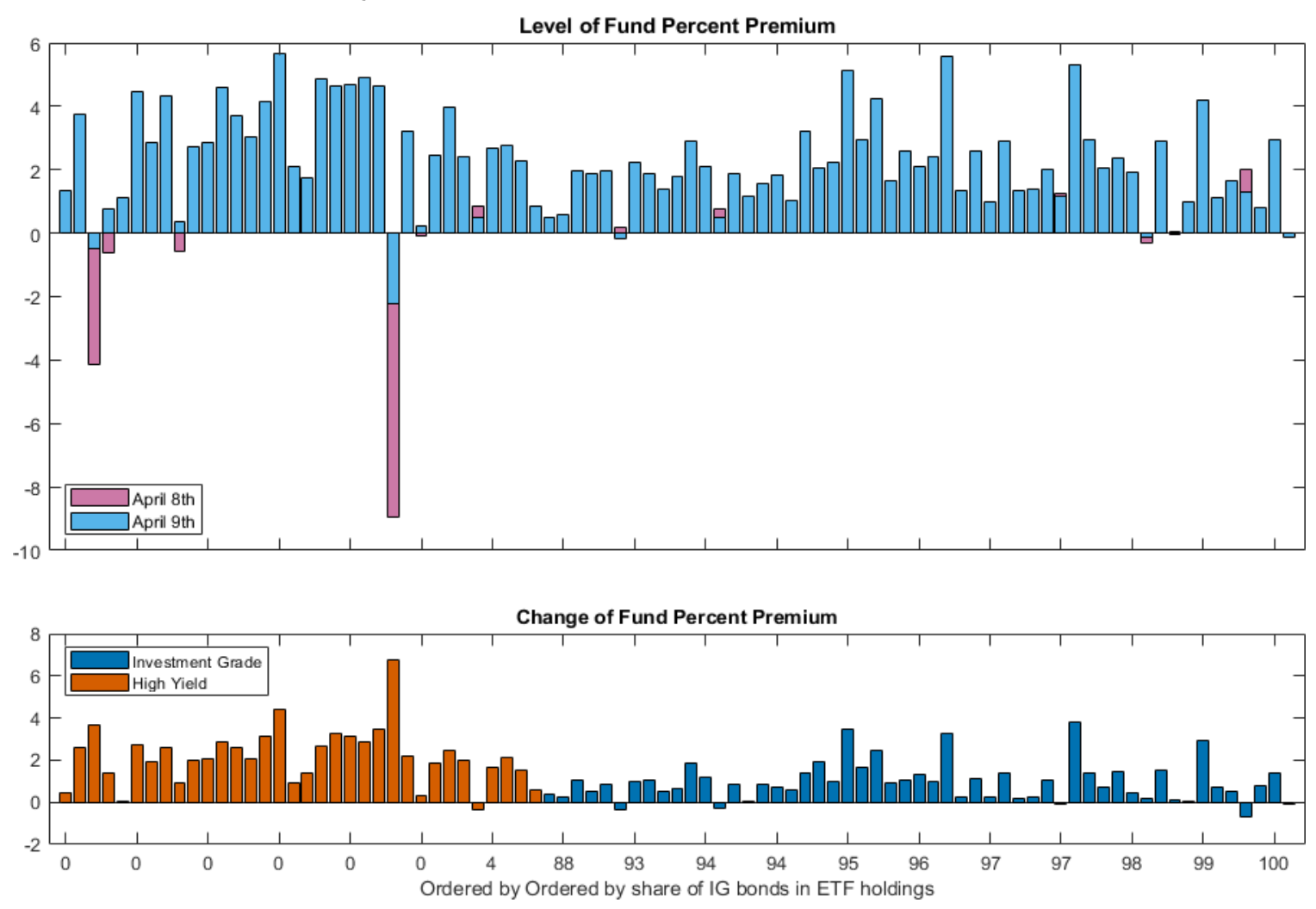
Figure 8: Does the ETF price change reflect liquidity or fundamental shocks to the value of underlying securities?

\section{Panel A}

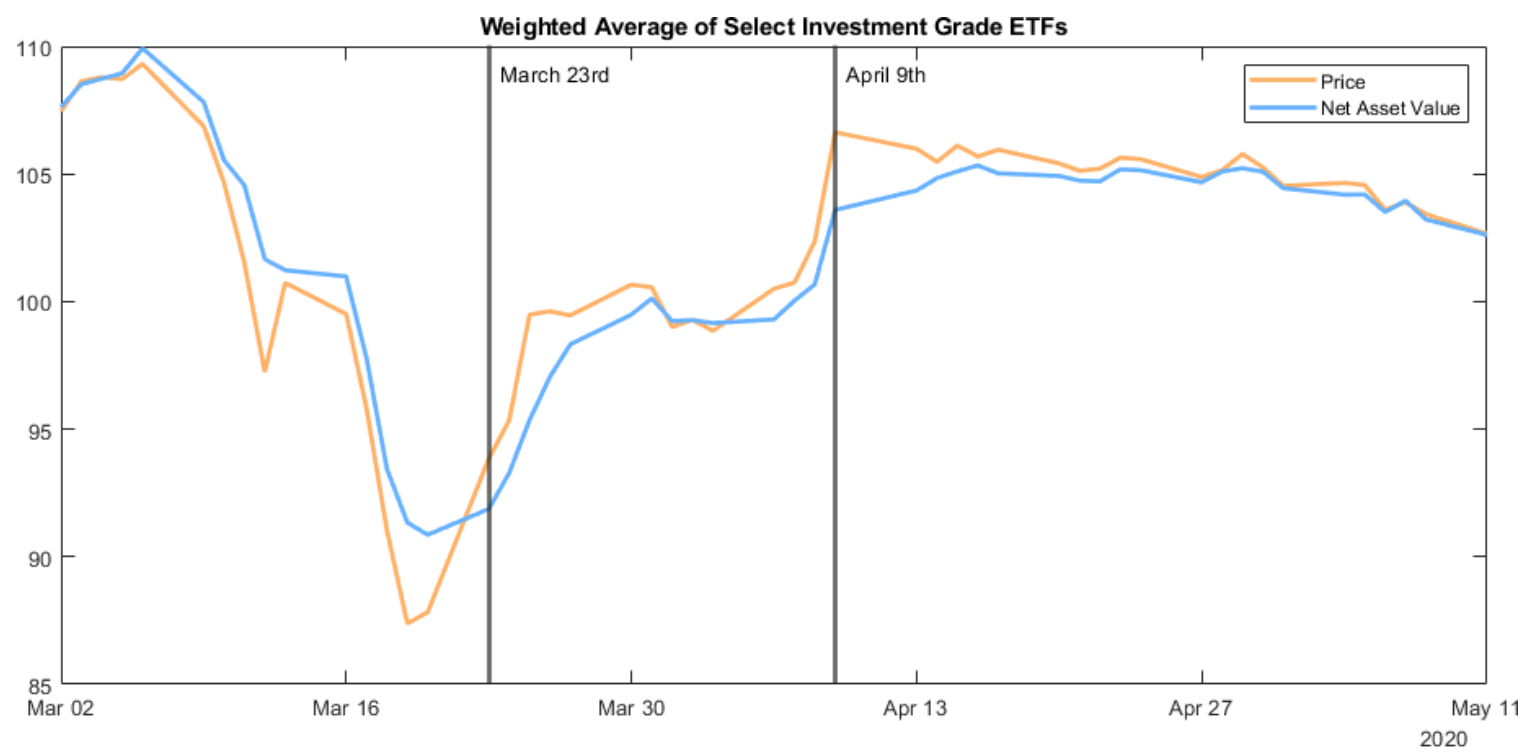

\section{Panel B}

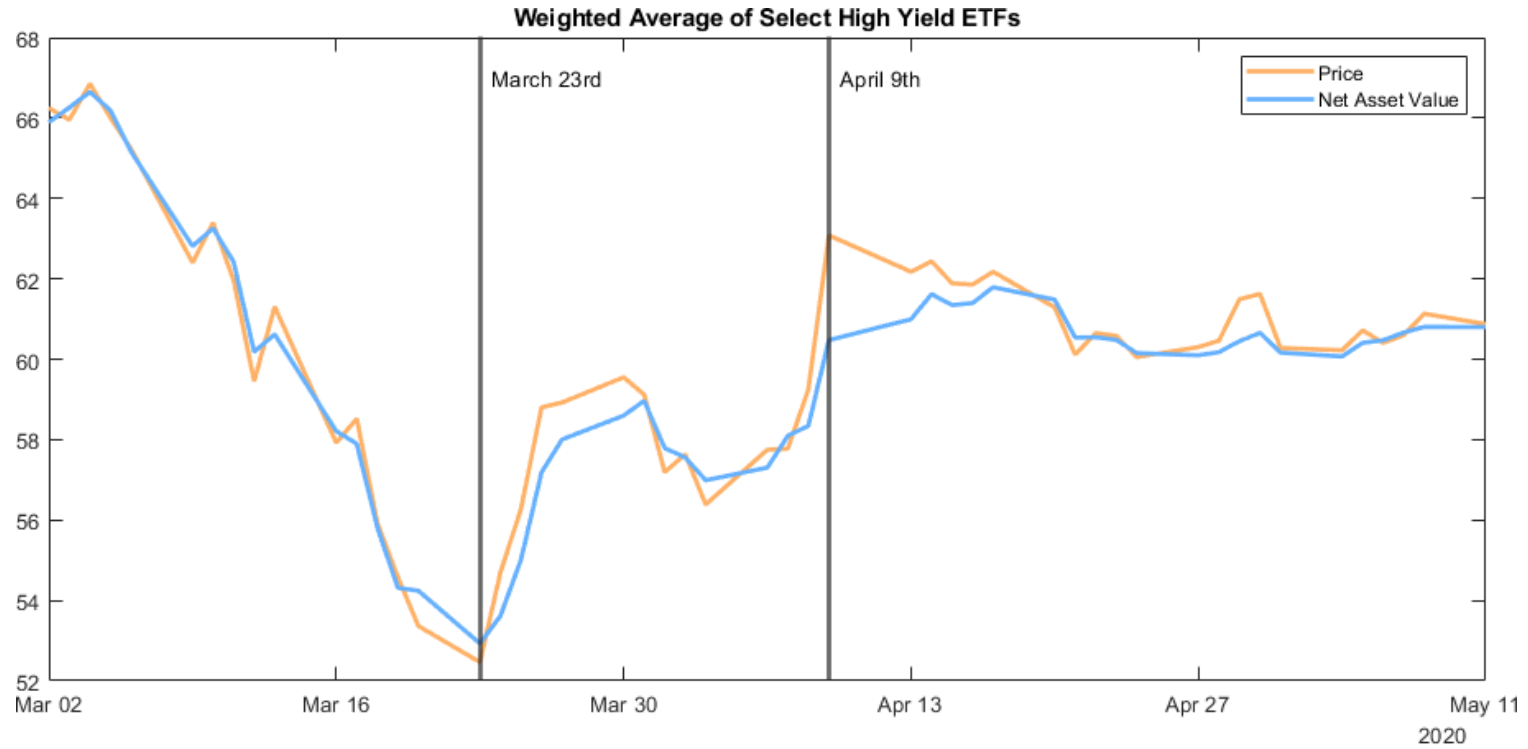




\section{Figure 9: Corporate Bond Issuance}

\section{Panel A: All Bond Issuance}

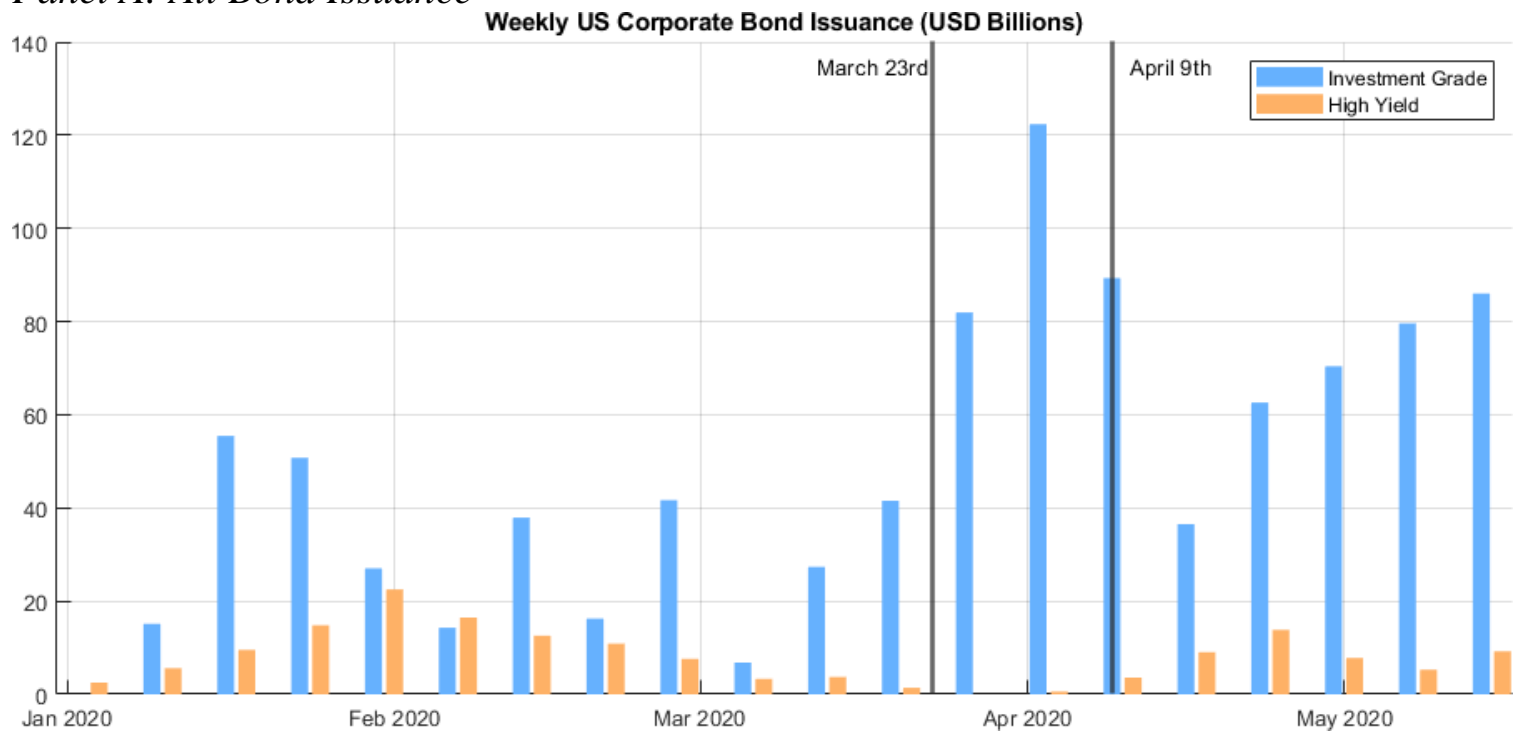

Panel B: Issuance restricted by Fed's eligibility criteria

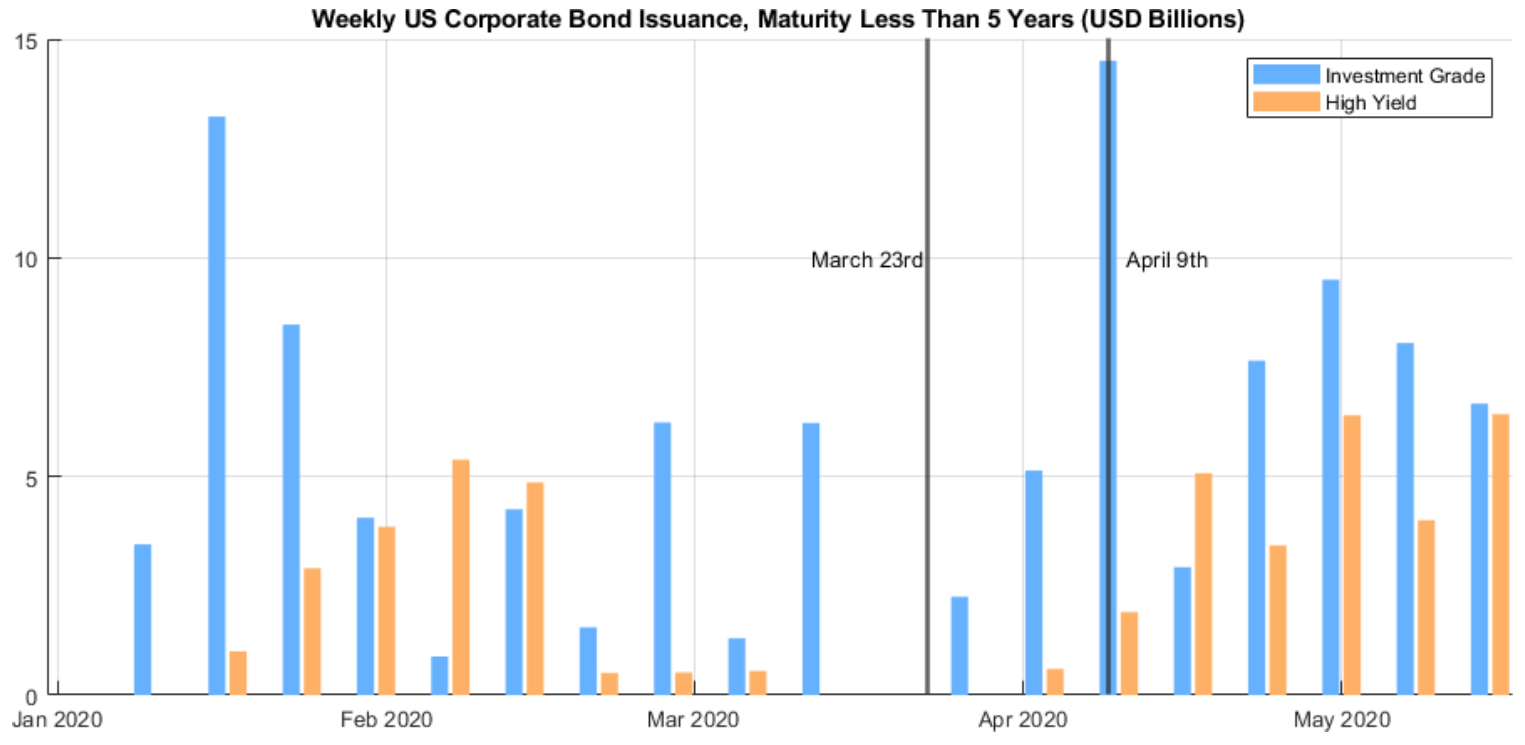




\section{References}

Abidi, Nordine, and Ixart Miquel-Flores (2018). "Who Benefits from the Corporate QE? A Regression Discontinuity Design Approach," ECB Working Paper No. 2145.

Barbon, Andrea and Virginia Gianinazzi (2019). "Quantitative Easing and Equity Prices: Evidence from the ETF Program of the Bank of Japan." Review of Asset Pricing Studies, v 9 n 2019.

Bernanke, Ben S. 2020. "The New Tools of Monetary Policy." American Economic Review, 110 (4): 943-83.

Charoenwong Ben, Randall Morck, and Yupana Wiwattanakantang (2020). "Bank of Japan Equity Purchases: The Final Frontier in Extreme Quantitative Easing. Working Paper, March.

D’Amico, Stefania and Iryna Kaminska (2019). “Credit Easing versus Quantitative Easing: Evidence from Corporate and Government Bond Purchase Programs," Bank of England Staff Working Paper, 825, September.

D'Amico, Stefania and Thomas B. King (2013). "Flow and Stock Effects of Large-Scale Treasury Purchases: Evidence on the Importance of Local Supply," Journal of Financial Economics, vol. 108, pp. 425-448.

Dannhauser, Caitlin D. (2017). "The impact of innovation: Evidence from corporate bond exchange-traded funds (ETFs)." Journal of Financial Economics 125 (2017) 537-560.

Flannery, Mark, Mahendrarajah Nimalendran, Sugata Ray, and Amir Yousefi (2017). "Using ETF Premia to Measure Corporate Bond Liquidity." Working Paper, November.

Gagnon, Joseph, Matthew Raskin, Julie Remache, and Brian Sack, 2011, The financial market effects of the Federal Reserve's large-scale asset purchases, International Journal of Central Banking 7, 3-43.

Gilchrist, Simon, David Lopez-Salido, and Egon Zakrajsek (2015). "Monetary Policy and Real Borrowing Costs at the Zero Lower Bound," American Economic Journal: Macroeconomics, vol. 7, pp. 77-109.

Gilchrist, Simon and Egon Zakrajsek, (2013). "The Impact of the Federal Reserve's Large-Scale Asset Purchase Programs on Corporate Credit Risk," Journal of Money, Credit and Banking, vol. 45, pp. 29-57.

Greenwood, Robin, Samuel Hanson, and Gordon Liao (2018). "Asset Price Dynamics in Partially Segmented Markets," Review of Financial Studies, vol. 31, pp. 3307-3343. 
Haddad, Valentin, Alan Moreira, and Tyler Muir (2020). "When Selling Becomes Viral: Disruptions in Debt Markets in the COVID-19 Crisis and the Fed's Response." Working Paper, May 7.

Hao, Xiaoting, Donghyun Kim, Hong Kee Sul, and Qinghai Wang (2019). "Underlying bond return predictability by ETF returns.” Working Paper December 2019.

Harada, Kimie and Tatsuyoshi Okimoto (2019). "The BOJ's ETF Purchases and Its Effects on Nikkei 225 Stocks.” RIETI Discussion Paper Series 19-E-014.

Junge, B., and A. B. Trolle. 2015. "Liquidity Risk in Credit Default Swap Markets." Swiss Finance Institute Research Paper no. 13-65, August.

Krishnamurthy, Arvind and Annette Vissing-Jorgensen (2011). "The Effects of Quantitative Easing on Interest Rates: Channels and Implications for Policy," Brookings Papers on Economic Activity, 34, 215-287.

Lettau, Martin, and Ananth Madhavan (2018). "Exchange-Traded Funds 101 for Economists." Journal of Economic Perspectives, Volume 32, No 1, 135-154.

Mamaysky, Harry (2018). “The Time Horizon of Price Responses to Quantitative Easing," Journal of Banking and Finance, vol. 90, pp 32-49.

Nam, Jayoung (2017). "Market Accessibility, Corporate Bond ETFs, and Liquidity." Working Paper, Kelley School of Business, Indiana University Bloomington, November 30 .

Nozawa, Yoshio and Yancheng Qiuy (2020). "The Corporate Bond Market Reaction to the COVID-19 Crisis.” Working Paper, April 18.

Poterba, James M. and John B. Shoven (2002). "Exchange-Traded Funds: A New Investment Option for Taxable Investors." American Economic Review Papers and Proceedings vol. 92, No 2, 422-27.

Todorov, Karamfil (2018). "Quantify the Quantitative Easing: Impact on Bonds and Corporate Debt Issuance," Journal of Financial Economics, forthcoming.

Zaghini, Andrea (2019). "The CSPP at Work: Yield Heterogeneity and the Portfolio Rebalancing Channel," Working Paper Series 2264, European Central Bank. 